Portland State University

PDXScholar

8-1-2018

\title{
Experimental and Numerical Investigation on the Bond Strength of Self-sensing Composite Joints
}

\author{
Shafique Ahmed \\ University of Delaware \\ Thomas Schumacher \\ Portland State University, thomas.schumacher@pdx.edu \\ Jennifer McConnell \\ University of Delaware \\ Erik T. Thostenson \\ University of Delaware
}

Follow this and additional works at: https://pdxscholar.library.pdx.edu/cengin_fac

Part of the Civil and Environmental Engineering Commons

Let us know how access to this document benefits you.

\section{Citation Details}

Ahmed, S., Schumacher, T., McConnell, J., \& Thostenson, E. T. (2018). Experimental and numerical investigation on the bond strength of self-sensing composite joints. International Journal of Adhesion and Adhesives, 84, 227-237.

This Pre-Print is brought to you for free and open access. It has been accepted for inclusion in Civil and Environmental Engineering Faculty Publications and Presentations by an authorized administrator of PDXScholar. Please contact us if we can make this document more accessible: pdxscholar@pdx.edu. 


\section{Experimental and Numerical Investigation on the Bond Strength of Self-Sensing Composite Joints}

a. Department of Civil and Environmental Engineering, University of Delaware, USA

b. Department of Civil and Environmental Engineering, Portland State University, USA c. Department of Mechanical Engineering, University of Delaware, USA d. Department of Materials Science \& Engineering, University of Delaware, USA e. Center for Composite Materials, University of Delaware, USA

\section{Abstract}

Laboratory experiments demonstrate that a novel carbon nanotube (CNT)-based sensing layer embedded in the bondline of an adhesively bonded structural joint can detect and monitor deformation and damage progression of the adhesive layer. In this study, experimental and numerical investigations were performed to identify any effect of an embedded CNT-based sensing layer on the bond strength of that joint. To evaluate the mechanical behavior of such a bondline configuration, two sets of single-lap specimens, with and without sensing layer, were prepared and tested to determine the bond strengths of the respective types. Two-dimensional digital image correlation (2D DIC) was utilized to estimate the load-displacement response of the test specimens. Three-dimensional cohesive surface finite element models of the test specimens, with and without the sensing layer, were created and validated using the experimental measurements. It is shown that the embedded CNT-based sensing layer does not influence the bond strength of the single-lap joint.

Keywords: Adhesive joint, composite, debonding, cohesive zone modeling, experimental testing, carbon nanotube sensing layer, fracture mode mixity.

\section{Introduction and Motivation}

Most structures are composed of various members connected by structural joints and are the critical load-carrying paths in a structure. Adhesive joints are becoming increasingly popular

*Corresponding author at: Civil and Environmental Engineering, Portland State University, 1930 SW 4th Avenue, Portland, OR 97201, USA. E-mail address: thomas.schumacher@pdx.edu. Phone: +1-503-725-4199, Fax: +1-503-725-4282. 
since they may reduce stress concentrations, enable uniform load distribution, have better fatigue 29 properties, and can join different kinds of material (e.g., steel and fiber reinforced polymer (FRP)) which are advantages over employing traditional fasteners including rivets, bolts, welds, or other mechanical fastening techniques. Adhesive joints are expected to perform optimally under both sustained as well as cyclic loading. However, lack of design guidelines or modeling techniques to accurately capture the maximum load carrying capacity of adhesive joints or understand their behavior and failure mechanisms have led to overly conservative designs. Failure mechanisms of adhesive joints are difficult to characterize, especially for adhesively bonded composite joints. Different types of failure can occur in adhesive, adhesive-adherent interface, adherent depending on fabrication procedures, geometric configuration, loading conditions, and weather conditions. Therefore, adhesive joints are often considered as the weak link among structural elements. As a result, mechanical fasteners such as bolts are often added alongside the adhesive layer. Thus there is a critical need to monitor potential damage in the adhesive joints such as debonding.

Researchers have used various techniques to monitor and diagnosis adhesive bondlines, for example, fiber Bragg grating [1, 2], acoustic-laser technique [3], and ultrasonic technique [2]. Carbon nanotubes (CNT) have been used for in situ sensing of FRP using carbon nanotube networks [4]. Debonding between the adherents in a joint system can be detected by directly dispersing CNTs in the adhesive [5]. An approach has been proposed by Ahmed et al. [6] to monitor the adhesive joints and it has been successfully demonstrated that debonding damage can be detected by means of a CNT-based sensing layer embedded in the bondline. This layer is composed of a nonwoven fabric coated by CNTs and the nanotubes form an electrically conductive network where electrical/mechanical coupling is capable of detecting stresses in the joint offering potential for structural monitoring leading to more efficient joint designs and early warning of 51 failure.

In the finite element (FE) models to predict failure load of adhesively bonded joints, the bondline thickness can be neglected for a thinner adhesive layer. A thick adhesive bondline may 54 require for a misaligned structural joints. In this research, embedding a CNT-based sensing layer 55 requires a thicker than usually recommended bondline. Therefore, FE models with a thicker 56 adhesive layer, compare to other studies [7, 8], were developed. In addition, inclusion of the 
sensing layer in the bondline may enhance potential stress concentration. The CNT-based sensing layer embedded in bondline was also included in the current study.

This research evaluates the critical performance of the bondline of the CNT-based sensing layer through developing a FE model and validating the model with laboratory tests. The specific objectives of this study were to (a) to establish the strength, and failure mode of single-lap joints that have thick adhesive bondlines with and without embedded CNT sensing layers, (b) develop an FE model to accurately predict the observations, and (c) compare the FE modeling results with additional data from the literature. bondline, were tested. The test setup and specimen dimensions are shown in Figure 1. Ten specimens were prepared and tested for each set. The composite plates were fabricated from 16 plies of M40J carbon/epoxy prepreg (Toray Composite Materials America, Inc.) by curing at a temperature of $135^{\circ} \mathrm{C}$ and a pressure of $296 \mathrm{kPa}$ in an autoclave for 120 minutes. The steel plates were sandblasted to create uniform surface roughness and promote adhesion. The composite laminates were prepared by sanding the surface by hand with 320 grit silicon carbide abrasive paper. The abraded surfaces were then cleaned with alcohol. A two-part epoxy paste adhesive (Hysol 9309.3 NA, Henkel North America), was used to join the steel and composite plates. A uniform bondline thickness of $2.0 \mathrm{~mm}$ was maintained for both sets of specimens (with and without embedded sensing layer). The adhesive layer was cured at $82^{\circ} \mathrm{C}$ for an hour according to the manufacturer's instructions. The CNT-based sensing layer was prepared by dipping an aramid veil in a CNT sizing bath for depositing CNTs on the aramid fibers. The dipped aramid veil was dried and cut into desirable size which was embedded in the bondline during the application of adhesive material. Details about manufacturing and embedding the sensing layer can be found in Ahmed et

81 al.[6]. The location of the sensing layer in the bondline is shown in Figure 1 (c). A universal testing 82 machine (Instron 5985) was used to load the specimens in tension in displacement-controlled mode. The specimens were loaded to failure at a constant rate of $13 \mathrm{~mm} / \mathrm{min}$. 

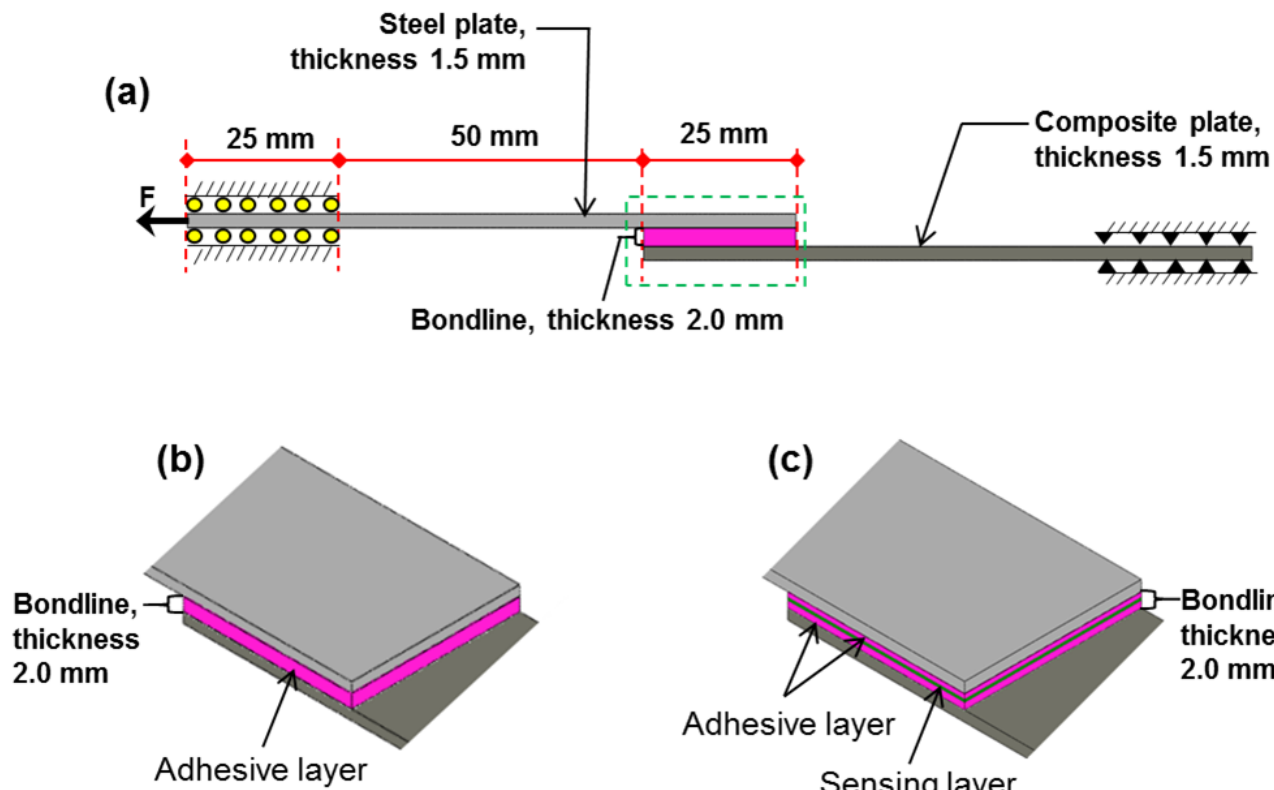

Adhesive layer

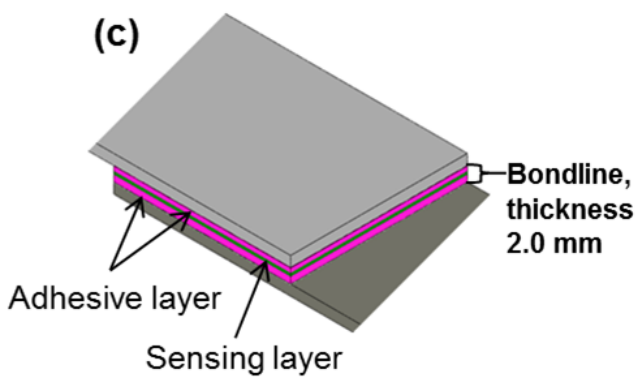

85 Figure 1: (a) Test specimen configuration and configuration of the overlap zone (b) without and

(c) with the embedded sensing layer.

All tests were recorded at 60 frames per second at a resolution of 720 x 1250 pixels using a digital single-lens reflex camera to analyze deformed shapes at various loading levels and to estimate true specimen end-to-end deformation using the two-dimensional digital image correlation (2D DIC) technique. This approach was used instead of a traditional displacement clip

91 gage, which cannot be properly attached to a non-symmetric specimen. Also, crosshead

92 displacement is not representative of specimen displacement as it includes grip slippage.

For the 2D DIC measurements, a speckle pattern was applied using spray painting on the

94 side of specimen's end tabs (see Figure 2 (a)) prior to testing. In this study, normalized cross-

95 correlation was used to estimate the true displacement between the specimens' end tabs using the sequence of recorded digital images, using the following equation [9] :

$$
\gamma(u, v)=\frac{\sum_{x, y}\left[f(x, y)-\bar{f}_{u, v}\right][t(x-u, y-v)-\bar{t}]}{\left\{\sum_{x, y}\left[f(x, y)-\bar{f}_{u, v}\right]^{2} \Sigma_{x, y}[t(x-u, y-v)-\bar{t}]^{2}\right\}^{1 / 2}}
$$
where, $f$ is the search area; $t$ is the target area; $\bar{t}$ is the mean of the target subset and $\bar{f}_{u, v}$ is the mean of $f(x, y)$. A rectangular shape target subset was selected that has a distinguishable variation

100 in gray level, on the edge of each of the spackle-patterned end. Based on the expected displacement 101 of the end tab, the search areas were selected by offsetting the target subset. Figure 2 (b) shows a 
102 typical distribution of normalized cross correlation. The position of this distribution identifies the 103 location of the target subset for the corresponding loading levels which was used to estimate rigid 104 body displacement of the target subset. Figure 2 (c) shows the displacement of a target subset that 105 represents the displacement of the corresponding end tab. True specimen deformations are then 106 calculated using the relative displacements of the end tabs. Two specimens were also instrumented 107 with linear variable differential transformers (LVDT) to compare with the 2D DIC displacement 108 measurement. The LVDT was attached near to one of the end tabs and an extension piece was 109 attached near to the other end tab to measure the displacement (shown in Figure 2(a)). In addition, 110 one test specimen was instrumented with three strain gages mounted on the steel adherend in the 111 overlap region with one mounted in the center of the overlap and two at each edge to validate the 112 FE model.

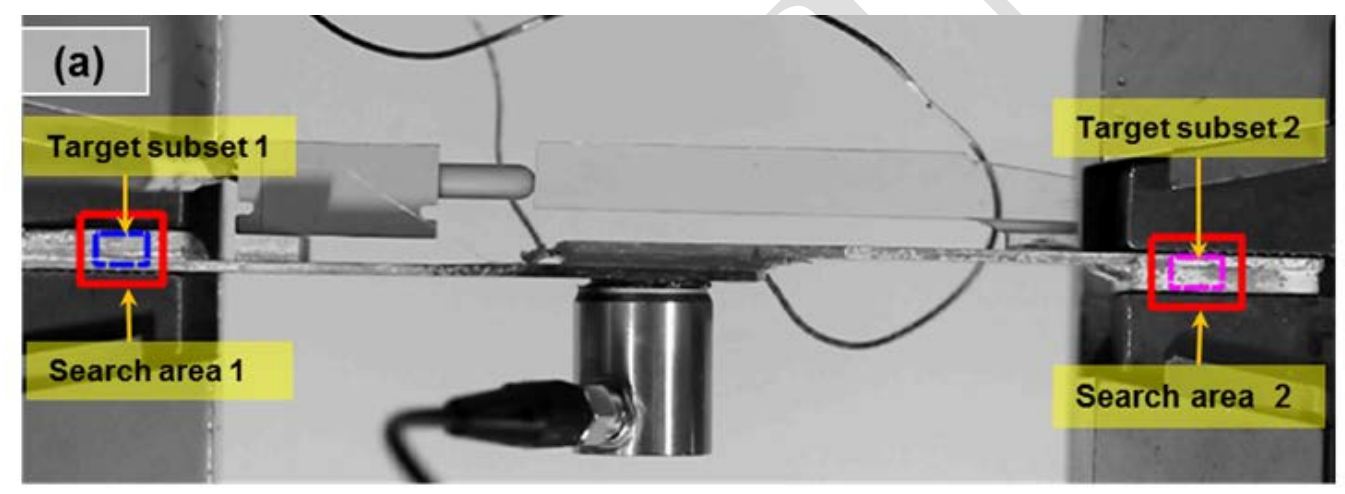

(b)

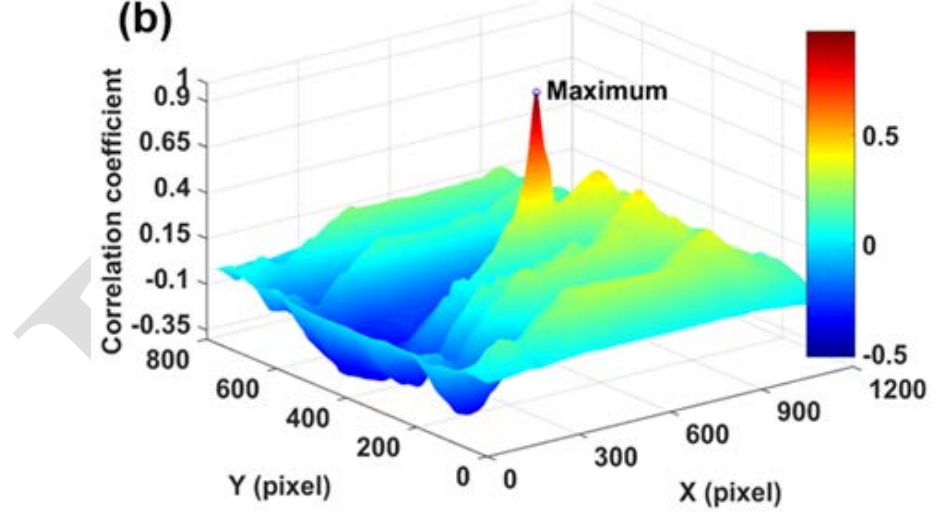

(c)

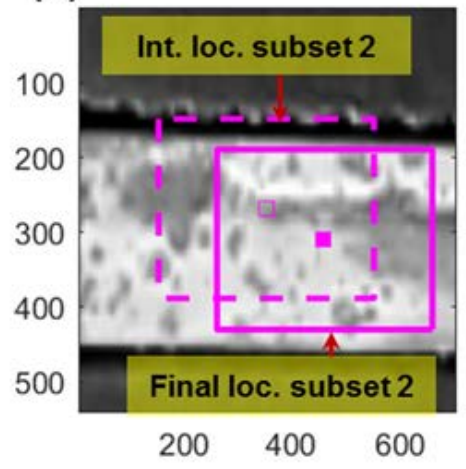

Figure 2: (a) Typical search areas and target subsets to estimate the specimen deformation and 115 attached LVDT (top) and acoustic emission sensor (bottom, data not analyzed for this paper), (b)

116 computed normalized cross-correlation coefficient to find the best match of a target subset in the 117 search area, and (c) sample speckle pattern in the search area with initial and final location of a target subset. 
Figure 3 shows the average failure load of the single-lap joints without and with sensing 120 layer, $9.6 \mathrm{kN}$ and $9.7 \mathrm{kN}$, respectively. A two-sample $t$-test confirmed that no statistically 121 significant difference exists between the observed failure loads for the specimens with and without 122 the embedded sensing layer. Also, the failure mechanism for both sets of specimens was similar. 123 Figure 4 shows typical failure surfaces for both sets of specimen. As shown in Figure 4, interfacial 124 failure was observed in both sets of specimen and some carbon fibers were pulled out from the 125 adherent (composite plate) all specimens of both specimen types. Thus, the CNT-based sensing 126 layer does not influence the bond strength (in terms of failure load) or failure mechanism.

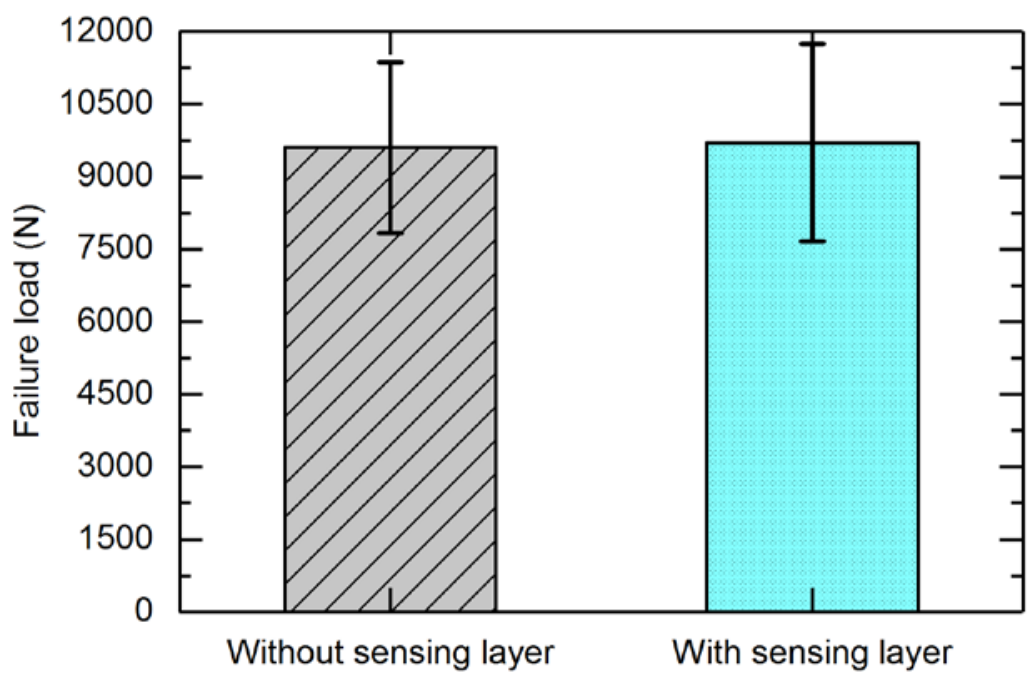

128 Figure 3: Comparison of experimentally obtained average failure load of the single-lap joints 129 without and with sensing layer. The error bars are located at plus/minus one standard deviation.

(a)

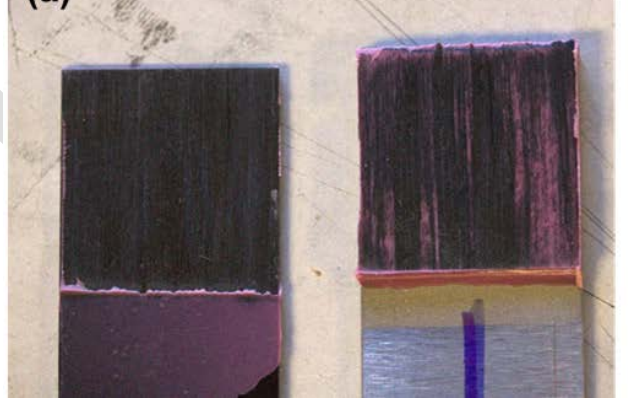

(b)

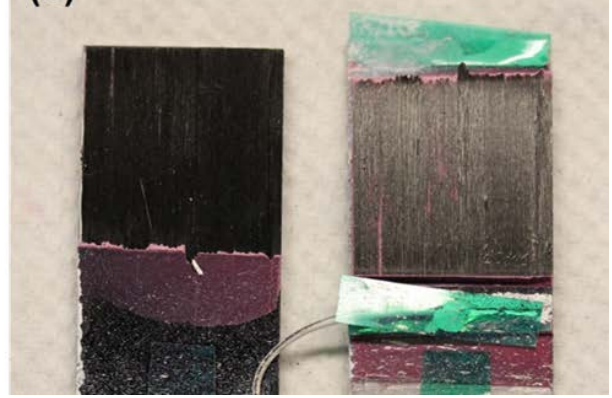

131 Figure 4: Photos showing typical failure surfaces of single-lap joints: (a) without and (b) with sensing layer. 
Figure 5 shows the crosshead displacement of the testing machine compared to the 134 specimen displacement measured using LVDT sensors and computed 2D DIC displacements. It 135 can also be observed that even though the test was run in displacement control, the specimen 136 experiences varying deformations due to slippage of the specimen in the grips. Mounting a LVT 137 sensor on the single-lap joint can be difficult as the LVDT may rotate depending on the mounting 138 location, which would add an additional displacement component. This is why optical 139 measurements were utilized in our characterization Figure 5 shows that the displacement measured 140 by the LVDT sensor mounted on the specimen and the computed 2D DIC displacements match closely. The obtained load-displacement responses were utilized to validate the FE model.

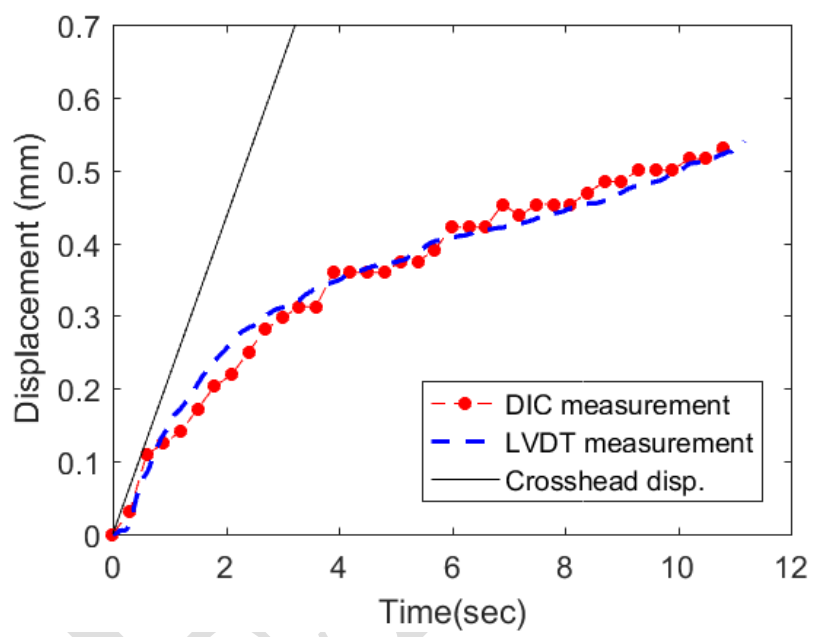

Figure 5: Comparison between crosshead, LVDT, and 2D DIC measured displacements.

\section{Finite Element Modeling of the Single-Lap Joint}

\section{Damage Modeling Approach}

There are three major modeling techniques available to model adhesive bond joints: (a) stress based (continuum mechanics), (b) fracture mechanics based, and (c) damage modeling. Damage modeling enables capturing the complete response of the structure including predicted maximum load carrying capacity and damage progression. In this research, a damage modeling approach was utilized. Two different approaches are available for damage modeling: (i) continuum approach and (ii) local approach. The difference between local and continuum approach is how damage can form and propagate in the model. In the local approach, paths and surfaces and in the continuum approach, finite areas and volumes can be predefined for damage formation and 
154 propagation, for 2D and 3D models, respectively. Gonçalves et al. [10] demonstrated that 3D 155 analysis can better resemble experiments by estimating significantly different stress distributions 156 from 2D analysis in a simple single-lap joint configuration. To perform the damage analysis using 157 the 3D local cohesive zone (CZ) approach, damage propagation path(s) and zero thickness 158 surface(s) need to be predefined. A zero thickness cohesive surface in an interface can be achieved 159 by moving the slave nodes onto the master surface.

160 Our damage modeling combines the aspects of strength-based approach, to define damage 161 onset, and fracture mechanics approach, to simulate damage propagation (debonding). In CZ 162 modeling approach, the purpose of the $\mathrm{CZ}$ is to simulate damage (eventually leading to fracture) 163 using a constitutive model of cohesive surface (Eq. 2) which is separated from the bulk material 164 responses. Figure 6 shows the separation kinematics of surfaces $S_{A}^{o}$ and $S_{B}^{o}$. The relative 165 displacement of homologous points ( $\mathrm{X}$ and $\mathrm{X}_{\mathrm{p}}$ in Figure 6 ) is known as the displacement jump, $166 \delta(X)=\eta-\eta_{p}^{o}$ where $\eta=f_{a}(X) ; \eta_{p}^{o}=f_{b}\left(X_{p}\right)$ and $f_{a}$ and $f_{b}$ represent the nodal maps describing 167 displacement between deformed surfaces $\left(\mathrm{S}_{\mathrm{A}}\right.$ and $\left.\mathrm{S}_{\mathrm{B}}\right)$ and undeformed surfaces $\left(\mathrm{S}_{\mathrm{A}}{ }^{0}\right.$ and $\left.\mathrm{S}_{\mathrm{B}}{ }^{0}\right)$.

168

169

170

171 172 CZ are given by:

173

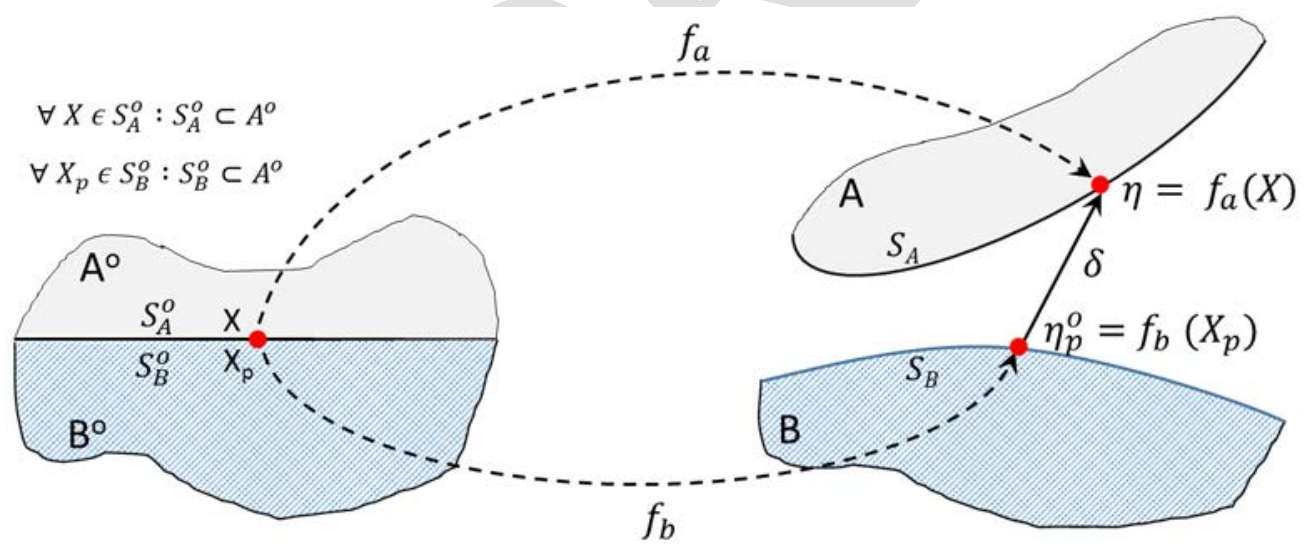

Figure 6: Cohesive interactions are illustrated to define the displacement jump.

The components of the local interface traction (including normal and tangential) can be computed from the bilinear traction-separation laws (Eq.2) [11]. The traction components $\left(\sigma_{i}\right)$ in

$$
\sigma_{i}= \begin{cases}K_{i} \delta_{i} & \text { if } 0 \leq \delta_{i} \leq \delta_{o, i} \\ \left(1-d_{i}\right) K_{i} \delta_{i} & \text { if } \delta_{o, i}<\delta_{i}<\delta_{\text {max }, i} \\ 0 & \text { if } \delta_{i} \geq \delta_{\text {max }, i}\end{cases}
$$


174 where, $i=$ direction of the corresponding traction component $=\mathrm{n}, \mathrm{s}, \mathrm{t} ; \mathrm{n}=$ normal direction; $s$ and $175 t=$ tangential direction of traction ; $K_{i}=$ penalty stiffness; $\delta_{i}=$ displacement jump; and, damage 176 parameter, $d_{i}=\frac{\delta_{\max , i}\left(\delta_{i}-\delta_{0, i}\right)}{\delta_{i}\left(\delta_{\max , i}-\delta_{0, i}\right)}$. Because $d_{i}$ is computed for $\delta_{\max , \mathrm{i}}>\delta_{\mathrm{i}}>\delta_{0, \mathrm{i}}$, thus $0<d_{i}<1$. The 177 reduction of stiffness can be simply computed by (1- $\left.d_{i}\right) K_{i}$ when $\delta_{\max , \mathrm{i}}>\delta_{\mathrm{i}}>\delta_{\text {o,i }}$ (Figure 7). If $\delta_{\mathrm{i}}>$ $178 \delta_{0, \mathrm{i}}$ (Figure 7) the stiffness values gradually decrease and the amount of decrease can be estimated 179 using a linear softening behavior. The stiffness goes back to zero when $\delta_{\mathrm{i}}$ approaches to $\delta_{\max , \mathrm{i}}$.

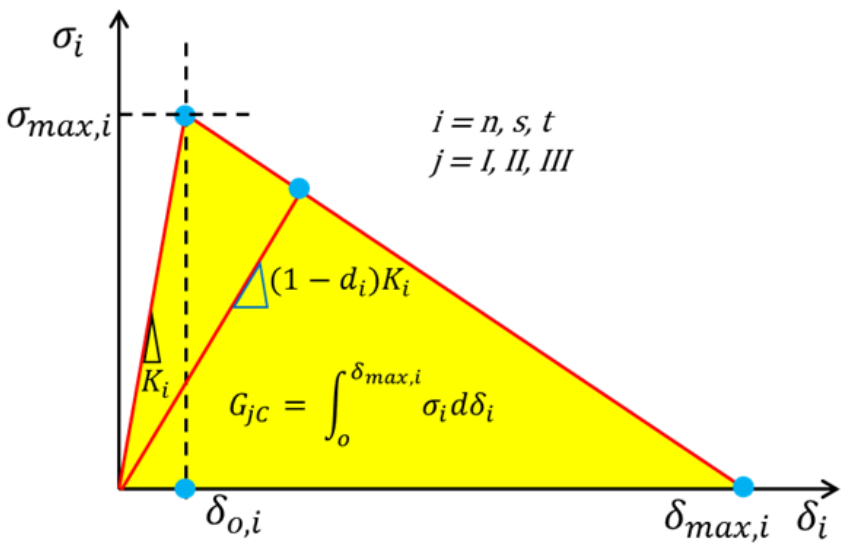

181 Figure 7: Pure mode constitutive relationship between traction and displacement jumps where $\mathrm{j}=$ type of pure mode.

Figure 7 shows the pure mode constitutive relationship between traction and displacement jump. $K$ is a numerical parameter $[7,10,12]$. The highest value of penalty stiffness, which will not introduce any numerical difficulty, e.g., spurious oscillations [13], can be used to ensure the least relative displacement of the interface nodes before the damage onset point. To simulate the thick adhesive, the adhesive stiffness is decoupled from the penalty stiffness. Eq. 3 [14] can be a guideline to determine $K_{n}$ values; where $\mathrm{A}>>1, \mathrm{E}_{3}$ is through thickness Young's modulus, and $t_{a d h}$ is thickness of adhesive. In general, in a pure tension mode and interface between two uniform thickness plates, $A>50$ introduces $2 \%$ stiffness loss due to presence of the interface which is

191 found accurate enough for the most problems [14]. For mode I, a simplified form of normal 192 stiffness $\left(K_{n}=E_{a d h} / t_{a d h}\right)$ has been used by de Moura et al. [15] which indirectly captured the effect 193 of adhesive layer thickness. The relationship between $K_{n}$ and $K_{t}$ in Eq. 4 ensures proper energy 194 dissipation [7, 13]. For a thin adhesive layer in a joint the normal stiffness of the bondline can be 
195 computed using Eq. 5 [16] when the maximum adhesive thickness has been limited by $t_{a d h}^{\max }=$

$196 \frac{2 G_{j C} E_{a d h}}{\left(\sigma_{\max , i}\right)^{2}}$, where $E_{a d h}=$ elastic modulus of adhesive and $\mathrm{G}_{\mathrm{jC}}=$ critical pure mode fracture energies.

$$
K_{n}=\frac{\mathrm{A} E_{3}}{t_{a d h}}
$$

$$
K_{n}=K_{t} \frac{G_{I I C}}{G_{I C}}\left(\frac{\sigma_{\max , n}}{\sigma_{\max , t}}\right)^{2}
$$

$$
K_{n}=\frac{E_{a d h}}{t_{a d h}}\left(\frac{1-v_{a d h}}{\left(1+v_{a d h}\right)\left(1-2 v_{a d h}\right)}\right)
$$
obtained from experimentations. In Abaqus [17], the penalty stiffness and maximum values of 202 normal and shear stresses are user defined parameters. criterion [18], can be used as the damage onset criterion [12, 19].

$$
\left(\frac{\left\langle\sigma_{n}\right\rangle}{\sigma_{\max , n}}\right)^{2}+\left(\frac{\sigma_{s}}{\sigma_{\max , s}}\right)^{2}+\left(\frac{\sigma_{t}}{\sigma_{\max , t}}\right)^{2}=1
$$

During the damage evaluation stage, B-K law [20] can capture the variation of energy 207 dissipation rate caused by the mode mixity where $G_{I C}, G_{I I C}$ and $G_{T C}$ are mode I, mode II and total critical strain energy release rate.

209

$$
G_{T C}=G_{I C}+\left(G_{I I C}-G_{I C}\right)\left(\frac{G_{I I C}}{G_{I C}+G_{I I C}}\right)^{\eta}
$$

$$
G_{T C}=G_{I C}+\left(G_{I I C}-G_{I C}\right)\left(\frac{G_{I I C}+G_{I I I C}}{G_{I C}+G_{I I C}+G_{I I I C}}\right)^{\eta}
$$

213 flexure (ENF) specimen can be utilized to obtain $\mathrm{G}_{\mathrm{II}}$. $\eta$ parameter obtains from fitting the 214 experimental values from DCB, ENF, and double cantilever beam (DCB) experiments [13, 20].

215 Experimentally obtained $G_{j C}$ and $\sigma_{i}$ can be used in Eq. (9) to evaluate damage in the model.

$$
G_{j C}=\int_{o}^{\delta_{\max , i}} \sigma_{i} d \delta_{i}
$$

217 For a linear softening material (Figure 7), the energy equation simplifies to 


$$
G_{j C}=\frac{1}{2} \sigma_{\max , i} \delta_{\max , i}
$$

$219 \quad G_{j C}$ and $\eta$ values are user defined parameters in the model which should be estimated based 220 on experiments as discussed above. Typical values of $G_{j C}$ can be used to perform damage modeling

$221[7,8]$. However, it is noteworthy that $G_{j} c$ and $\eta$ values control the model responses after the damage 222 initiation.

\section{Specimen Geometry and Meshing Approach}

224 FE models of a single single-lap joint without the sensing layer were created in ABAQUS

225 [17]. Actual dimensions of the steel and composite plates $\left(100.0 \times 25.4 \times 1.5 \mathrm{~mm}^{3}\right)$ and adhesive $226\left(25.4 \times 25.4 \times 2.0 \mathrm{~mm}^{3}\right.$, shown in Figure 1) and boundary conditions simulating the physical 227 conditions (shown in Figure 8) were used in the models. A study of mesh size sensitivity was 228 conducted and mesh scheme shown in Figure 9 (a) was adopted. General-purpose continuum 229 quadratic brick elements with 20 nodes (C3D20 [17]) were used to create the adherents and the 230 adhesive. 3D continuum interface element with 27 nodes (C3D27 [17]) were utilized for the CZ 231 neighboring adhesive elements. Zero thickness cohesive surfaces were created (as discussed in the 232 previous section) between adhesive and adherents, including steel-adhesive and composite233 adhesive interfaces (labeled A and B in Figure 8 (b)). These are created by co-locating the nodes 234 on the surface of the adhesive and the nodes on the interface surfaces of steel and composite plates.

235 The damage initiation zone has been selected according to the suggestion of Li et al.[21]. 236 Also, Gonçalves et al. [22] used similar damage initiation areas in their modeling approach. To 237 simulate the specimen with sensing layer, in addition to the modeling techniques described above, 238 a $0.45 \mathrm{~mm}$ thick layer with orthotropic material properties was introduced to simulate the sensing 239 layer inside the bulk adhesive layer (Figure 9 (b)) according to a typical bondline configuration of 240 specimen with sensing layer is shown in Figure 9 (c). A perfect bond between adhesive and sensing 241 layer interfaces was assumed considering that the sensing layer was completely infused within the 242 bulk adhesive materials (Figure 9 (c)). 


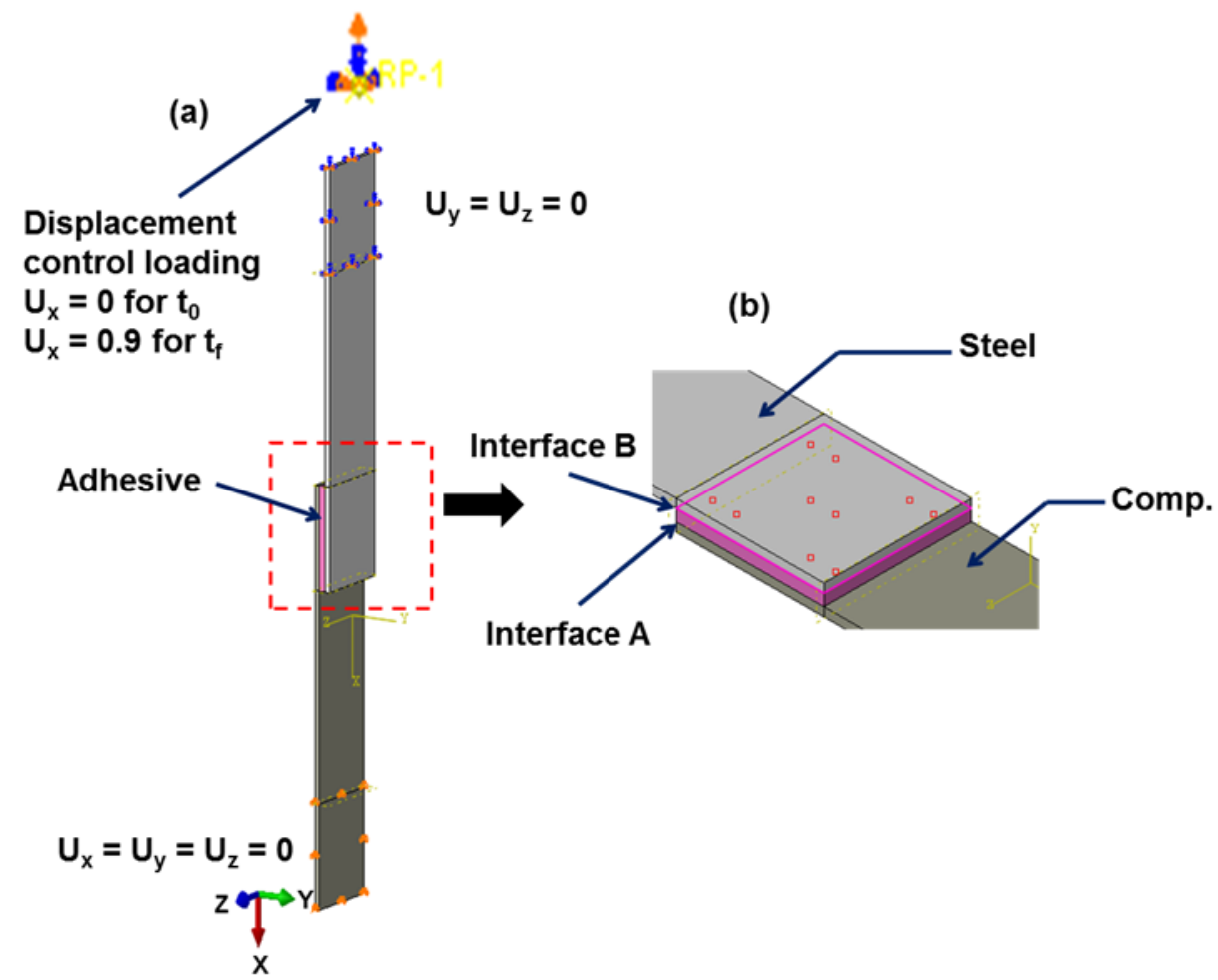

244 Figure 8: FE model of single-lap joint configuration with thick (2.0 mm) adhesive (a) boundary 245 conditions and (b) CZ interfaces.

(a)

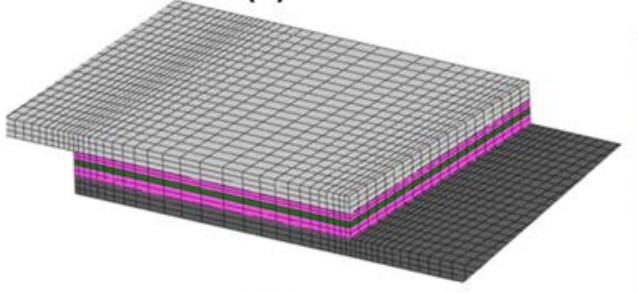

(b)

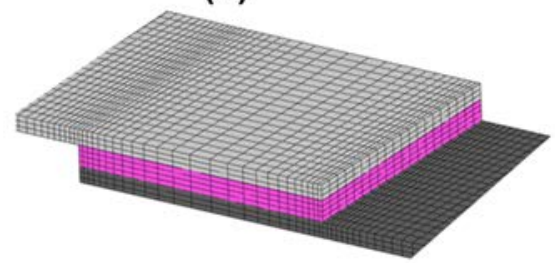

(c)

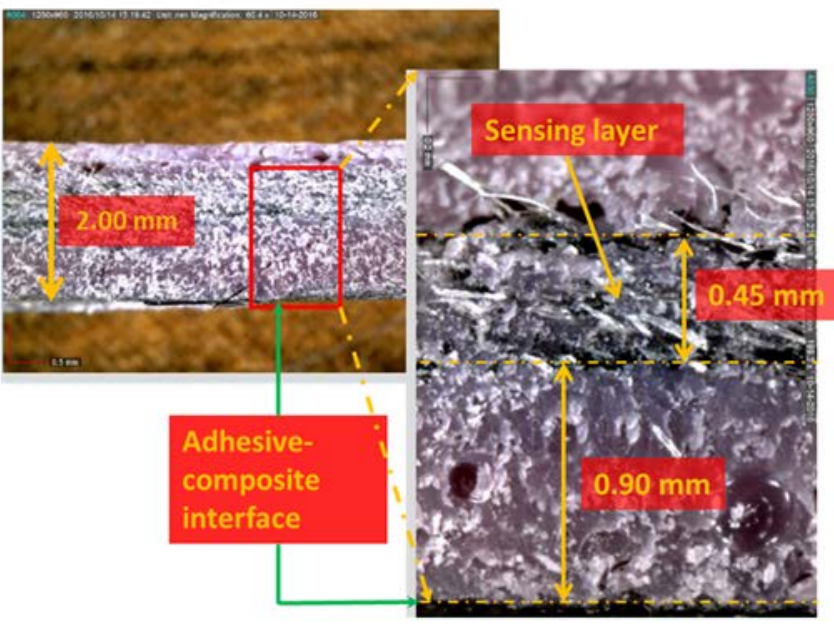

Figure 9: Meshing scheme (a) with a sensing layer, (b) without a sensing layer (c), and photographs showing the bondline of a typical test specimen with a sensing layer. 
Material properties and damage modeling parameters

Appropriate penalty stiffness for the interaction of cohesive interface, $K_{i}$ values, were 251 selected to provide sufficient stiffness as well as to avoid numerical problems as discussed in the

252 Damage Modeling Approach. Four different sets of penalty stiffness and a perfect interface (= tie 253 connection) were considered for evaluating the interfacial stiffness effects on global stiffness 254 change of the model. $K_{s}$ and $K_{t}$ values were considered to be identical and $K_{n}$ values were computed 255 using Eq. 4 to ensure proper energy dissipation. $K_{\mathrm{s}}$ values used in this investigations are $1 \times 10^{3}$, $2562 \times 10^{3}, 3 \times 10^{3}$, and $5 \times 10^{3} \mathrm{~N} / \mathrm{mm}^{3}$. Figure 10 shows the effect of this variation in interface 257 stiffness on the load-displacement response of the model without an embedded sensing layer. It 258 was found that the predicted maximum load carrying capacity increases along with the increase of 259 penalty stiffness; however, the increase of stiffness is insignificant and almost converging while 260 using the higher $K$ values. While comparing with the load-displacement response of the perfect 261 interface model (tie connection between adhesive and adherents), a maximum of 4.75\% global 262 stiffness reduction was found up to the damage onset point (of the numerical model) while using $263 K_{t}=3 \times 10^{3} \mathrm{~N} / \mathrm{mm}^{3}$. This stiffness reduction is considered to be sufficient for this simulation 264 given that the model with $K_{t}=5 \times 10^{3} \mathrm{~N} / \mathrm{mm}^{3}$ exited with an error of too many iterations required 265 for convergence. Thus for the further evaluation of the FE damage models, $K_{t}=3 \times 10^{3} \mathrm{~N} / \mathrm{mm}^{3}$ 266 was used. 


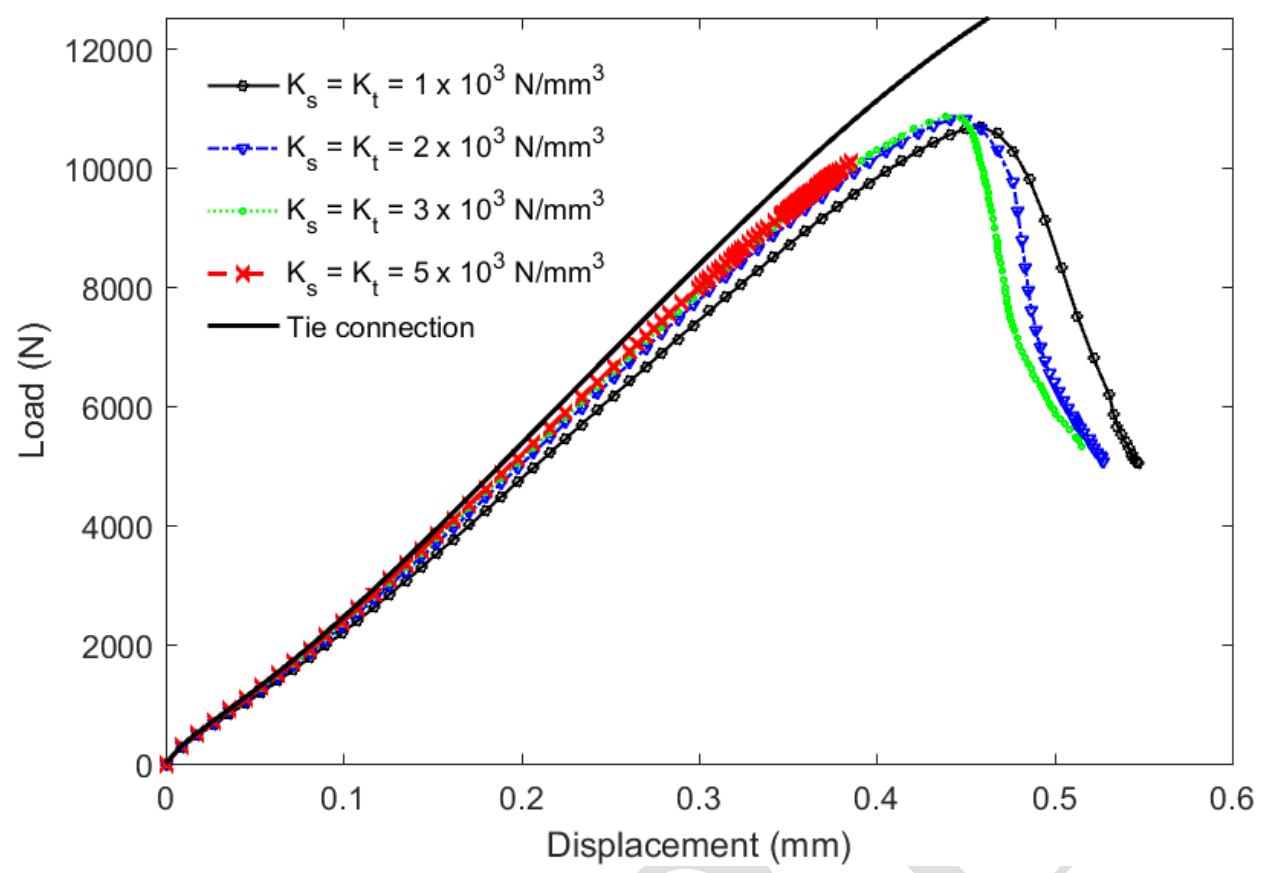

Figure 10: Effect of interface stiffness on the load-displacement response.

270 properties of Hysol adhesive (listed in Table 1) were taken from the experimental results by Kim 271 et al.[23]. Ramberg-Osgood (R-O) model (Eq. 11) [24] was used to replicate the elastic-plastic 272 behavior of steel similar to prior work [25] and adhesive (the required parameters are listed in 273 Table 1).

$$
\frac{\varepsilon}{\varepsilon_{\mathrm{o}}}=\frac{\sigma}{\sigma_{\mathrm{o}}}+\alpha\left(\frac{\sigma}{\sigma_{\mathrm{o}}}\right)^{\mathrm{n}}
$$

275 where, $\varepsilon_{o}=$ yield strain; $\sigma_{o}=$ yield stress; $\alpha=$ dimensionless constant representing yield offset; $n$ $276=$ hardening exponent.

277 Figure 11 (a) shows the measured stress-strain diagram and R-O fit. The hardening 278 exponent and yield offset values ( $n=24.4$ (Eq. 12) and $\alpha=1.07$ (Eq. 13)) were calculated using 279 the equations proposed by Kim et al. [25]

$$
n=\frac{\ln \left[\frac{E_{S} \varepsilon_{u}-\sigma_{u}}{0.002 E_{S}}\right]}{\ln \left(\frac{\sigma_{u}}{\sigma_{o}}\right)}
$$

$$
\alpha=\frac{0.002 \mathrm{E}}{\sigma_{o}}
$$


282 where, $\mathrm{E}_{\mathrm{s}}=$ elastic modulus of steel; $\varepsilon_{\mathrm{u}}=$ ultimate tensile strain of steel; $\sigma_{\mathrm{u}}=$ ultimate tensile 283 strength of steel.

284 It can be observed that better fit of stress-strain data can be obtained using $n=105$. The 285 values of $\mathrm{n}$ and $\alpha$ for adhesive material were obtained by R-O model fitting the Kim et al's [23] 286 experimental data.

(a)

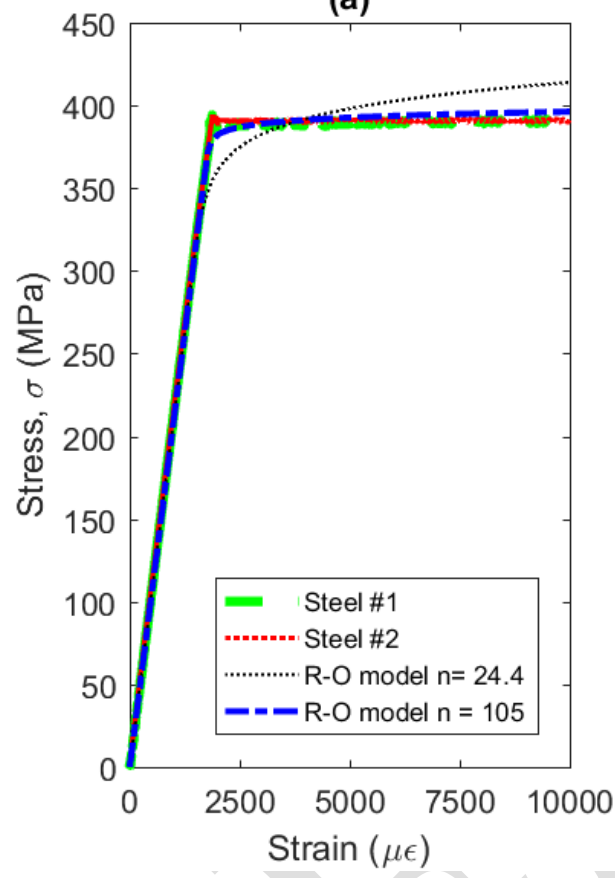

(b)

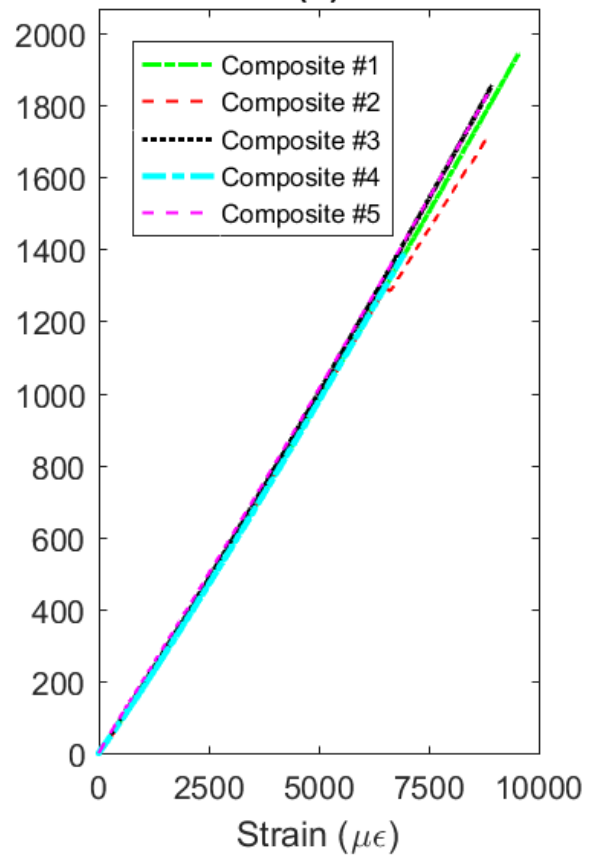

Figure 11: Tensile coupon test results of (a) steel plate, (b) composite plate.

Critical fracture energy values, $G_{j}$, were taken from the experimental results of Tomczyk 290 [26]. Ye’s criterion (Eq. 6) was utilized to predict the damage onset and B-K law (Eq. 8) [20] was 291 used to capture the energy dissipation variation due to the mode mixity and to evaluate damage 292 propagation. Since the ' $\eta$ ' value is unknown, extreme values (1.5 and 5.0) were utilized to evaluate 293 the effect on predicting the maximum load carrying capacity and results were discussed in FE 294 Model Validation section.

295 Orthotropic material properties were used to simulate the mechanical behavior of the 296 sensing layer. Elastic modulus along length and width of sensing layer were used 3875 MPa [27] 297 and elastic modulus of the sensing layer along the thickness direction was assumed to be that of 298 adhesive material considering the very low fiber volume fraction and orientation. Shear moduli 
299 were approximated to be $1000 \mathrm{MPa}$ and Poisson's ratio of the sensing layer was assumed to be 300 identical to the adhesive material.

301

Table 1. Material properties and damage parameters used for the advanced FE model.

\begin{tabular}{llll}
\hline Steel & Composite & Adhesive & Damage parameters \\
\hline $\mathrm{E}_{\mathrm{s}}=210 \times 10^{3} \mathrm{MPa} ;$ & $\mathrm{E}_{1}=200 \times 10^{3} \mathrm{MPa} ;$ & $\mathrm{E}_{\mathrm{a}}=2.62 \times 10^{3} \mathrm{MPa}$ & $\sigma_{\mathrm{max}, \mathrm{n}}=35 \mathrm{MPa} ;$ \\
$v_{\mathrm{s}}=0.3 ;$ & $\mathrm{E}_{2}=\mathrm{E}_{3}=8.4 \times 10^{3} \mathrm{MPa} ;$ & $;$ & For steel -adhesive interface, \\
$\mathrm{n}=105 ;$ & $v_{12}=v_{13}=0.3 ;$ & $v_{\mathrm{a}}=0.38 ;$ & $\sigma_{\text {max }, \mathrm{s}}=\sigma_{\mathrm{max}, \mathrm{t}}=27 \mathrm{MPa} ;$ \\
$\alpha=1.07 ;$ & $v_{23}=v_{21}=0.45 ;$ & $\mathrm{n}=5 ;$ & For composite -adhesive \\
$\sigma_{\mathrm{o}}=391 \mathrm{MPa}$ & $\mathrm{S}_{12}=\mathrm{S}_{13}=7.23 \times 10^{3}$ & $\alpha=0.1 ;$ & interface, \\
& $\mathrm{MPa} ;$ & $\sigma_{0}=32 \mathrm{MPa}$ & $\sigma_{\max , \mathrm{s}}=\sigma_{\max , \mathrm{t}}=26 \mathrm{MPa} ;$ \\
& $\mathrm{S}_{23}=3.79 \times 10^{3} \mathrm{MPa}$ & & $\mathrm{G}_{\mathrm{I}}=2.61 \mathrm{~N} / \mathrm{mm} ;$ \\
& $\mathrm{S}=$ shear modulus & & $\mathrm{G}_{\mathrm{II}}=\mathrm{G}_{\mathrm{III}}=5.22 \mathrm{~N} / \mathrm{mm}$ \\
\hline
\end{tabular}

FE Model Validation

303 Simulation of results with and without embedded sensing layer

304 Figure 12 shows that the load-displacement response and predicted failure load of the FE 305 models with and without sensing layer are practically identical to model the specimen with a 306 sensing layer embedded in the bondline. This agrees with the experimental findings. Thus it is 307 concluded that the sensing layer does not need to be considered in the FE model. Therefore, for 308 the subsequent evaluation of FE models, the response of a general model without a sensing layer 309 was utilized. 


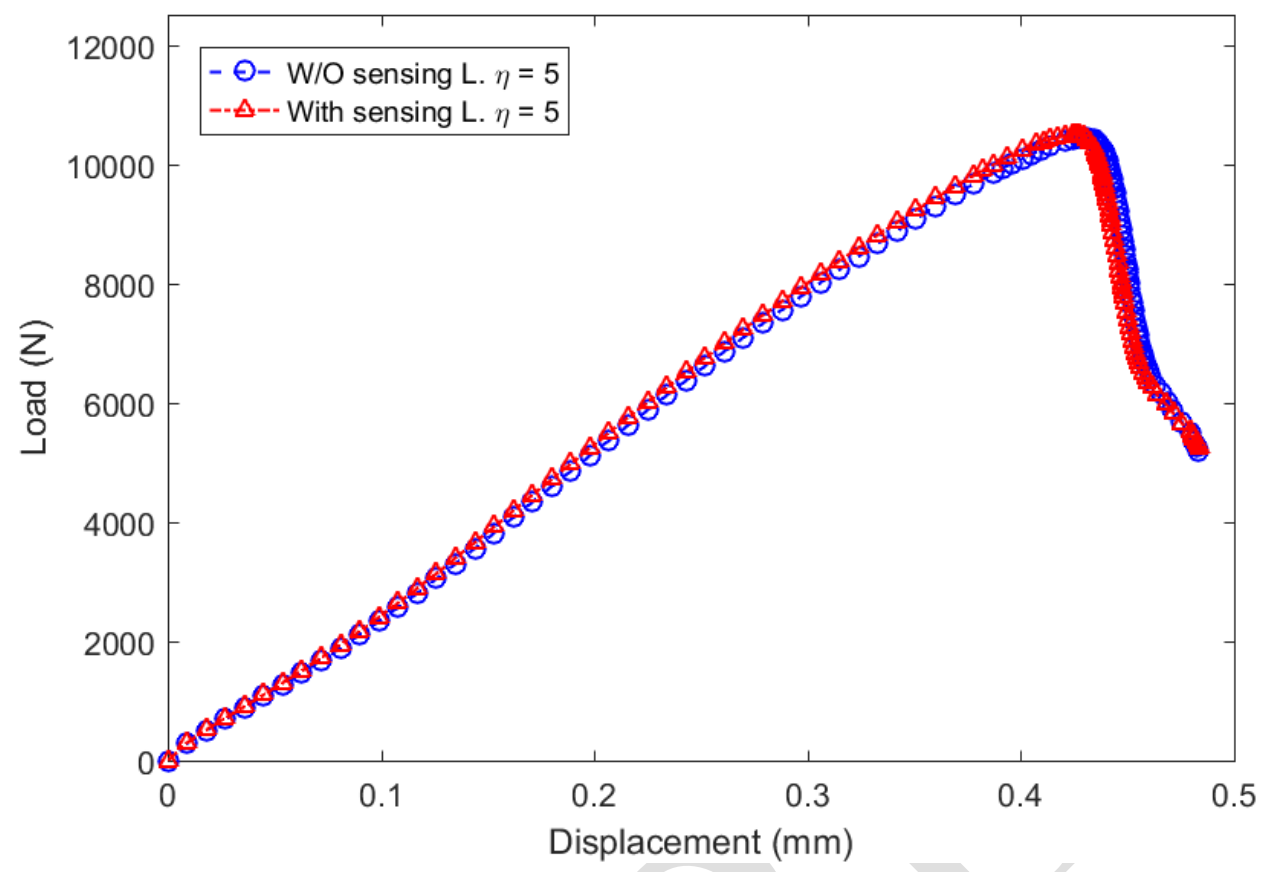

$311 \quad$ Figure 12: Load-displacement response of FE models with and without sensing layer.

\section{Comparison between Experimental Measurements and FE Results}

313 The experimentally obtained failure load of the single-lap joint were compared with that

314 of FE model. As previously discussed, in the simulation the B-K law [20] was utilized to the 315 estimate the total critical energy required for damage propagation under mixed mode conditions.

316 The curve fitting parameter of the B-K law, $\eta$, was not experimentally determined; therefore 2 317 extreme values for $\eta$ (1.5 and 5.0) were assumed according to the suggestion of Sarrado et al. [7] 318 and results from both are reported. It was found that the higher $\eta$ value predicts a lower maximum 319 load (see Figure 13), which is expected according to Eq. 8. Specifically, in mixed mode conditions, 320 a higher $\eta$ value estimates a lower total critical energy, which allows for an earlier damage 321 propagation, thus, produces a lower maximum failure load. FE element predictions of failure load 322 for the two extreme values of $\eta$ are $10.4 \mathrm{kN}(\eta=5.0)$ and $10.9 \mathrm{kN}(\eta=1.5)$, which are in a close 323 proximity of the average experimental measurements of the specimens without and with an 324 embedded sensing layer are $9.6 \mathrm{kN}$ and $9.7 \mathrm{kN}$, respectively. Figure 13 also compares the load325 displacement response of the FE models and the experimental measurements. It can be observed 326 from these data that the experimental measurements are in close agreement with the FE results. 


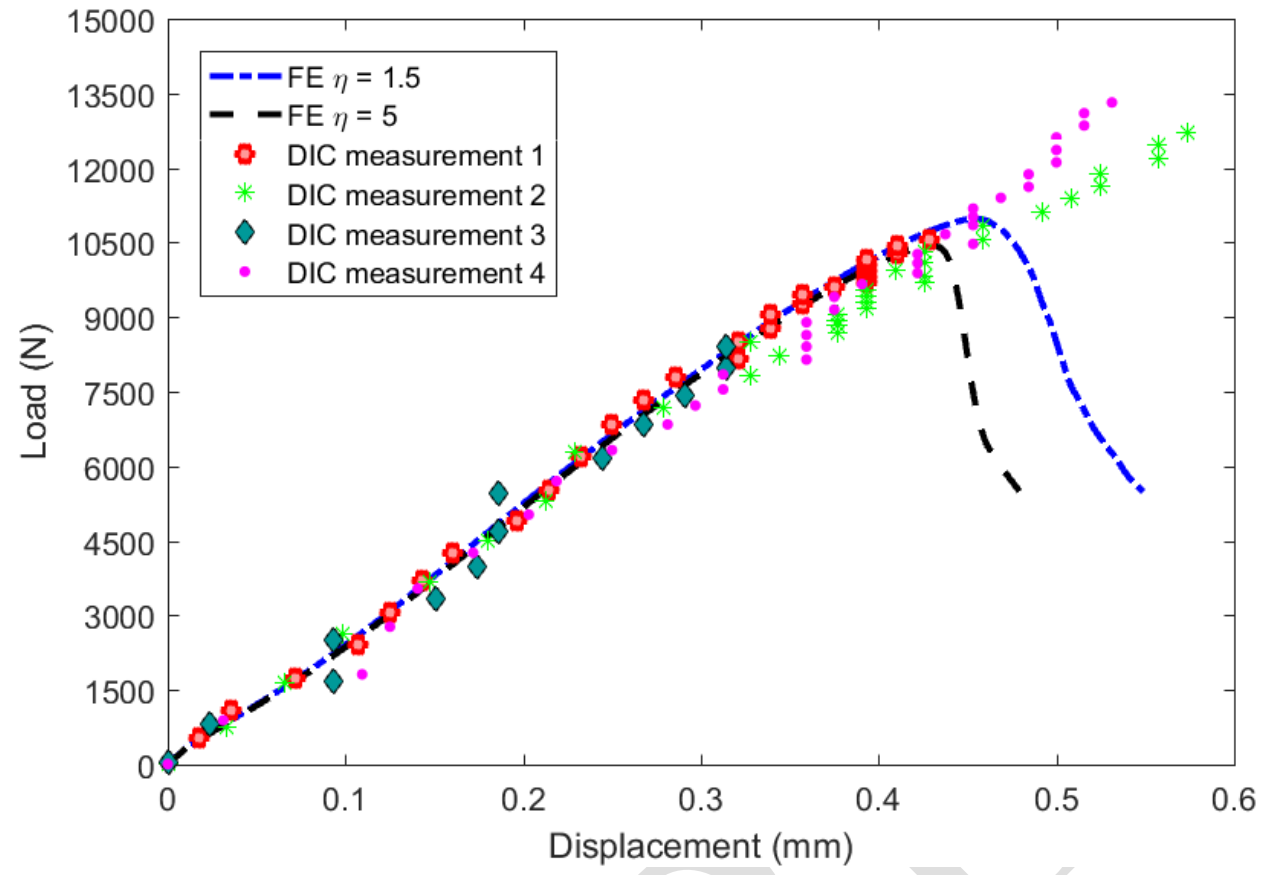

328 Figure 13: Load-displacement response of the FE models and four experimentally obtained 2D

Figure 14 shows a comparison between measured $\left(\varepsilon_{\mathrm{Exp}}\right)$ and computed $\left(\varepsilon_{\mathrm{FE}}\right)$ normal strains 331 at two load levels and three locations of strain gage (shown in the inset). Two loading levels were 332 selected to evaluate the FE response before and after numerical damage onset. It is evident that the 333 FE and experimental normal strain results match closely. 


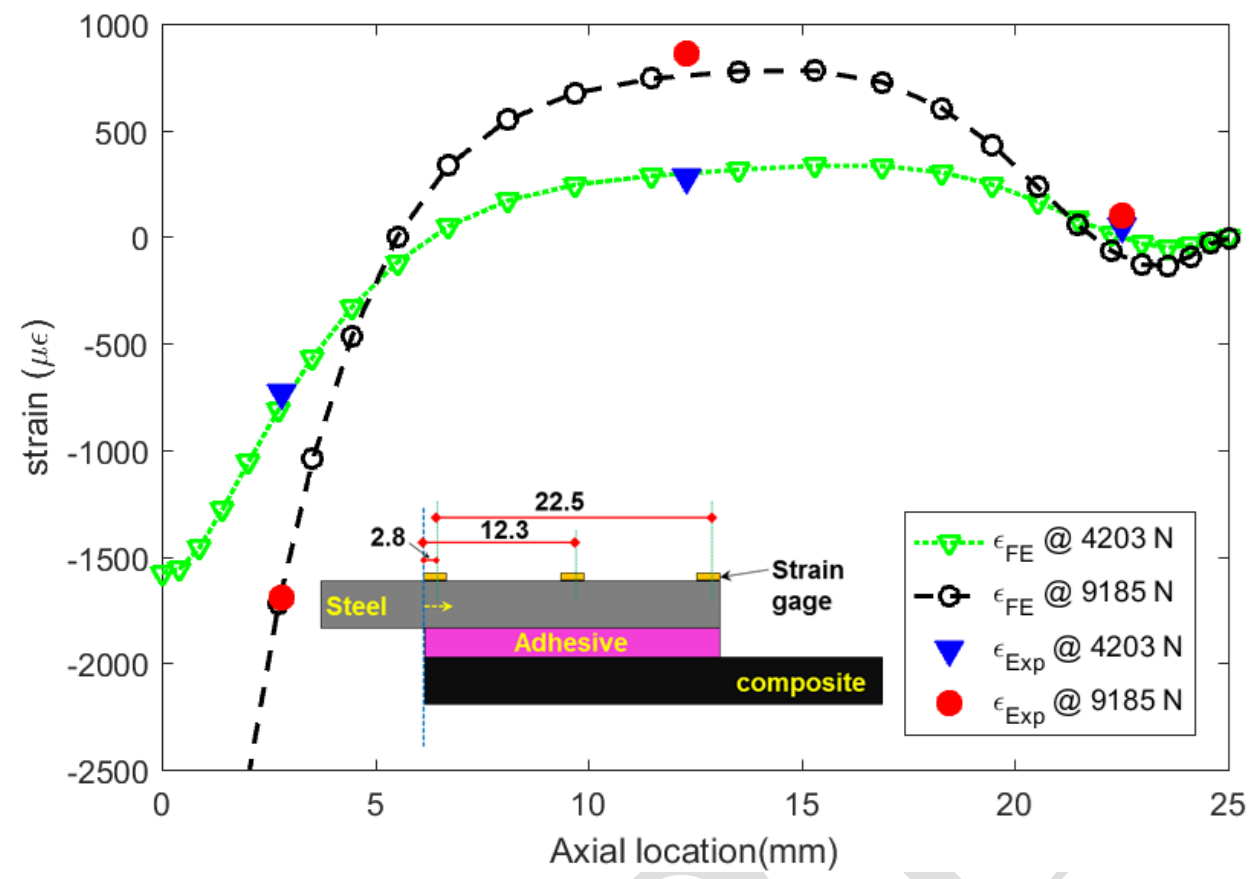

Figure 14: Comparison of experimental and FE normal strain in steel plate at two different loading levels. Strain gage locations are shown in the inset.

Figure 15 (a) and (b) show the normal traction and peel stress distribution in the $\mathrm{CZ}$ and at 339 the mid-thickness of the adhesive at two different loading levels, (a) immediately before numerical 340 damage onset and (b) at the maximum loading level. It was found that the peeling stress $\left(\sigma_{22}\right)$ and 341 normal traction $\left(\sigma_{n}\right)$ at $\mathrm{CZ}$ have identical trending stress distributions along the lap length. 342 Magnitudes of peeling stress at mid- thickness of the adhesive were less than the magnitudes of 343 that in the CZs. A similar behavior was also observed for the distribution of shear stress $\left(\sigma_{12}\right)$ and 344 tangential traction $\left(\sigma_{s}\right)$, which are shown in Figure 15 (c) and (d). It can also be seen that the 345 magnitude of shear stress increases with increasing load. Shear lag behavior can be evaluated by 346 integrating shear stress at the mid-thickness of the adhesive along the length of the joint and 347 comparing with the total transferred load (which in this case is total load applied). 
(a)

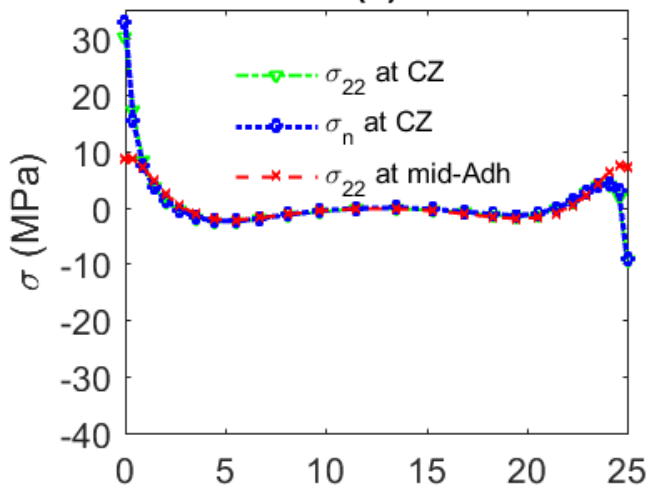

(c)

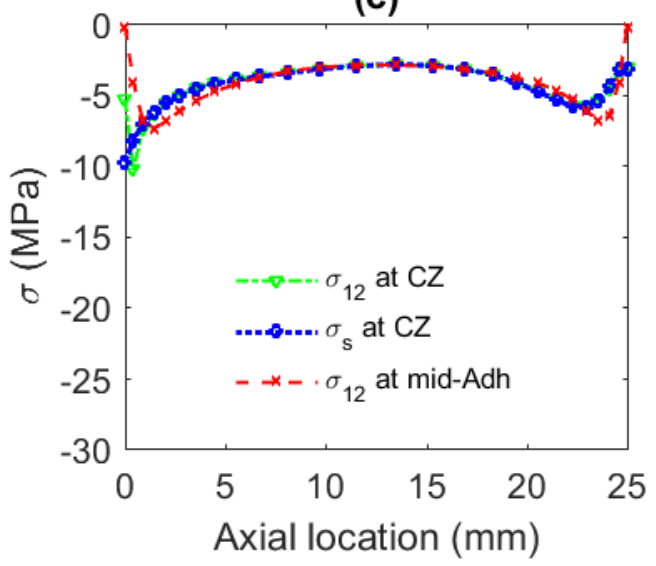

(b)

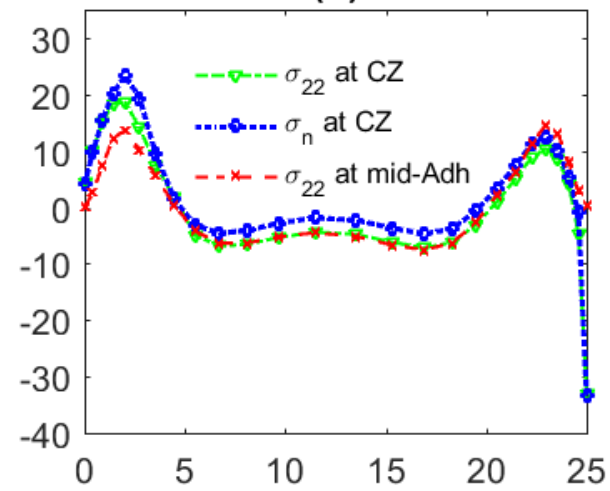

(d)

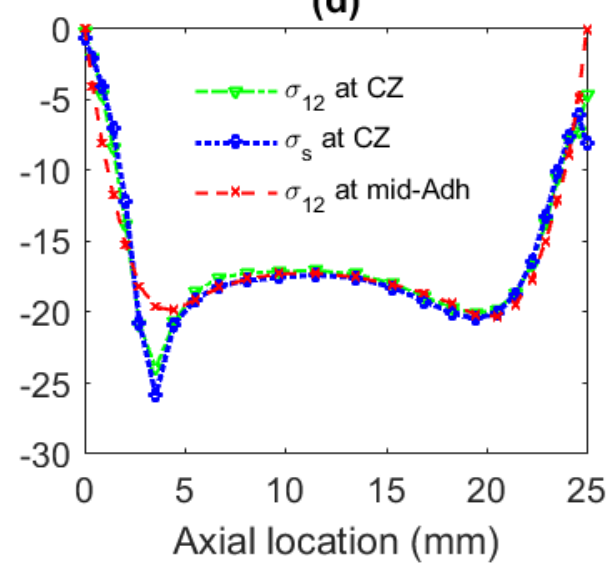

Figure 15: Cohesive normal traction and peel stress distribution in the CZ and in the midthickness of adhesive: (a) before numerical damage onset and (b) at the maximum loading level; cohesive tangential traction and shear stress distribution in cohesive zone and in the midthickness of adhesive: (c) before numerical damage onset and (d) at the maximum loading level.

Failure Mechanism

Figure 16 shows a comparison of experimental and FE damage stages of the specimens with an embedded sensing layer. The FE model was able to simulate the large distortion of the 356 substrates under the maximum loading level which was produced by the large eccentricity induced 357 from the thick adhesive layer (as shown in Figure 16 (c) and (d)). Also, FE model was able to 358 simulate the debonding propagation in the interface between adhesive and adherents which agree 359 with experimental findings as clearly illustrated by Figure 16 (e) and (f). It should be noted that the crack initiation in the bondline varied from specimen to specimen, which became evident from 
the digital videos. In other words, the ratio of crack initiation load to failure load varied among

362 specimens. Since no microscope was used during the experiments, a detailed characterization of 363 crack initiation and failure mode was not performed.

(a)

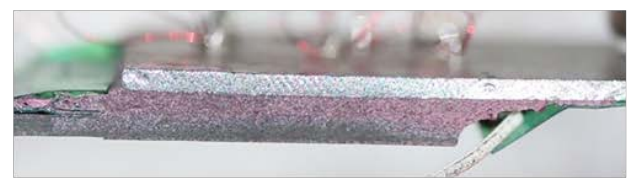

(c)

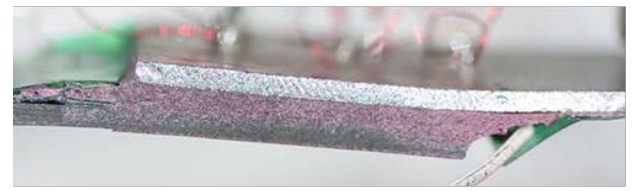

(e)

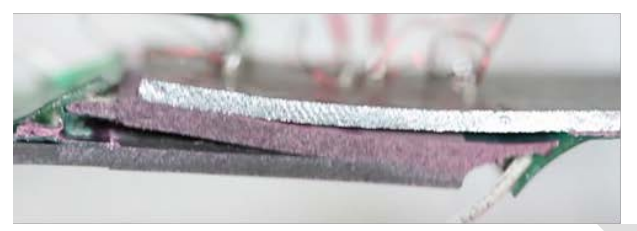

(b)

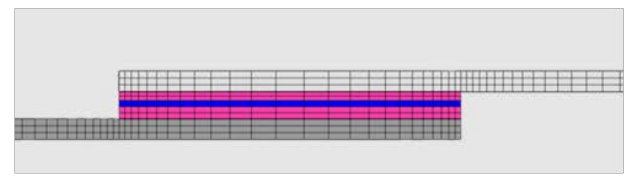

(d)

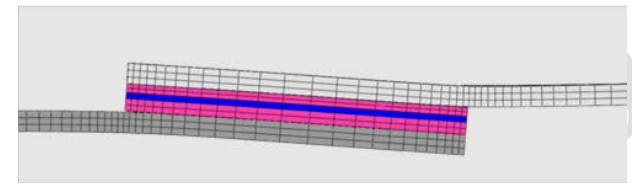

(f)
364

365

366

367

368

369

370

371

372

373

374

375

376

377

378

379

380

Figure 16: Different stages of damage propagation in experimental and FE results, respectively:

(a) and (b) initial condition, (c) and (d) at maximum loading level, (e) and (f) post peak deformation. (a), (c), and (e) are photos taken during the experiment and (b), (d), and (f) are snap shots produced from the FE modeling.

Stability of the relationship between tractions and displacement jumps were evaluated for this model and are shown in Figure 17. Both parameters were normalized, by $\sigma_{\max , i}$ and $\delta_{\max , i}$ computed using Eq. 10. Considering the negligible quantity of $\sigma_{t}$, it is not presented here. The linear softening behavior with lower stiffness values can be observed in Figure 17. The damage onset points are mathematically determined based on Ye's criterion (Eq. 6) [18]. In general, it is evident that the constitutive relationship between traction and displacement jumps was stable for the utilized FE discretization (meshing scheme) throughout the displacement domain. Thus, for this FE model (where cohesive surfaces are considered in between the thick adhesive layer and both adherents), both potential instabilities, which can be generated from the corresponding relative physical properties (high interface stiffness relative to low adhesive stiffness) and FE discretization that is too coarse [28] were avoided successfully. 


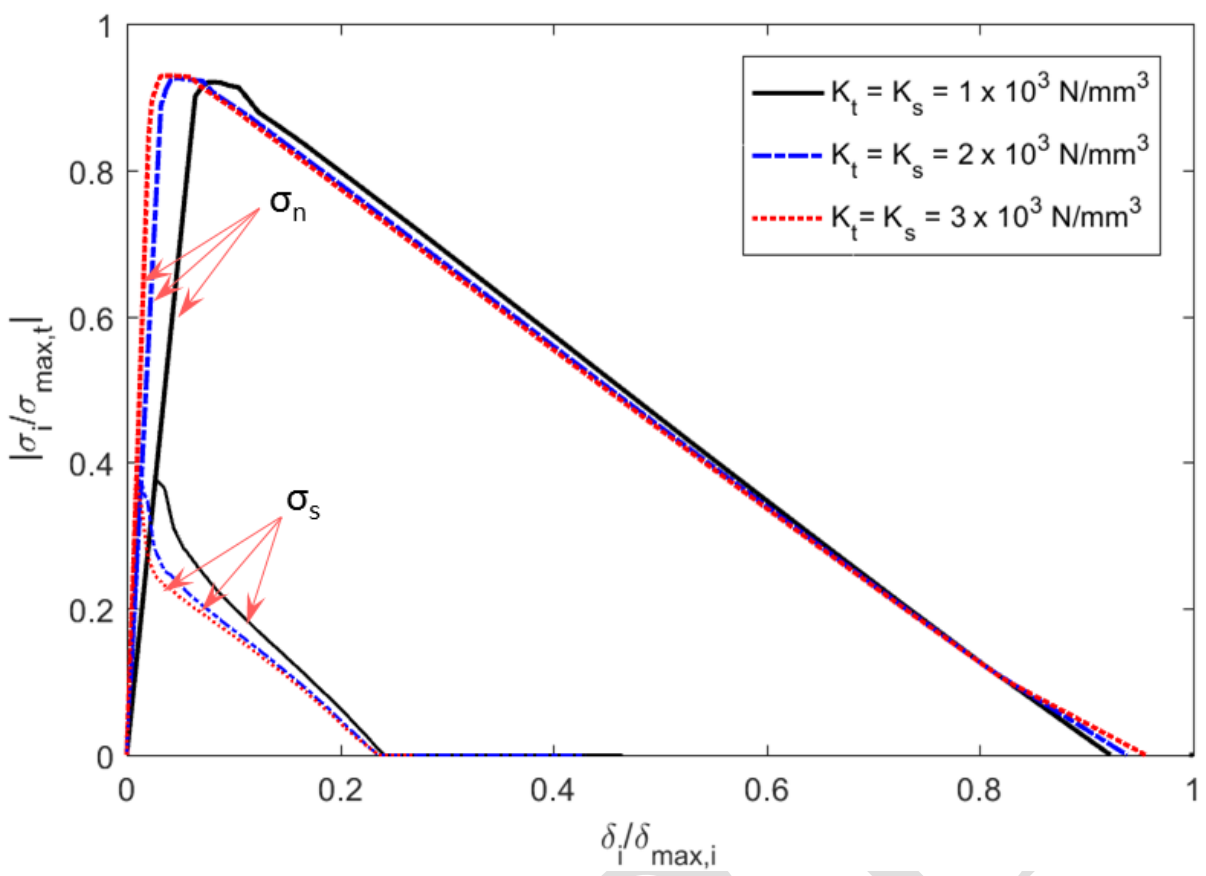

Figure 17: Normalized traction vs. displacement jumps.

\section{3}

\section{Model Validation: Influence of Adhesive Thickness}

In this research, all the specimens had $2 \mathrm{~mm}$ bondline thickness. Therefore, the influence of adhesive thickness on the shear strength of single lap joints investigated by da Silva et al. [8] using three different kinds of adhesives have been evaluated by the FE models. Those experimental results were also used by Sarrado et al. [7] to evaluate their proposed finite-thickness cohesive element. Simulation results from applying the modeling techniques used in the present study were compared with those of da Silva et al. [8] and Sarrado et al. [7], and are discussed in this section. The mechanical reasons of bond strength degradation due to the thicker bonlines are discussed from based on current simulation results.

The geometry of da Silva et al.'s [22] test specimens are shown in Figure 18, where the adhesive thicknesses $t_{a d h}=1.0 \mathrm{~mm}$ (b), $0.5 \mathrm{~mm}$ (c), and $0.2 \mathrm{~mm}$ (d). As part of the present work, FE models of the single-lap joints were created in ABAQUS using the same modeling techniques discussed above. Specifically, actual dimensions of adherents (120 x 25.4 × $2.0 \mathrm{~mm}^{3}$ steel plates) and adhesive (25.4 x $25.4 \times t_{a d h} \mathrm{~mm}^{3}$ (Figure 18 (a) to (d)) and appropriate boundary conditions (Figure 18 (a)) were used in the model. Also, general-purpose continuum quadratic brick elements 
398 (C3D20) were used to create adherents and adhesive and 3D continuum interface element (C3D27) 399 were utilized for the interface between adhesive and adherents. The meshing scheme is shown in 400 Figure 18 (b) to (d).

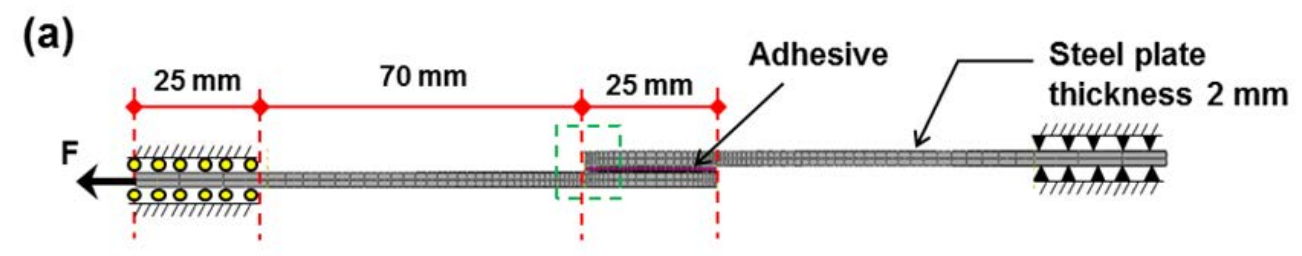

(b)

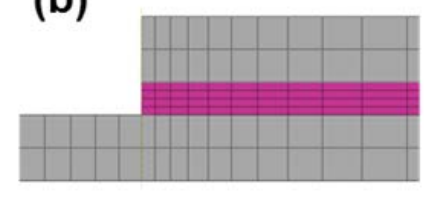

(c)

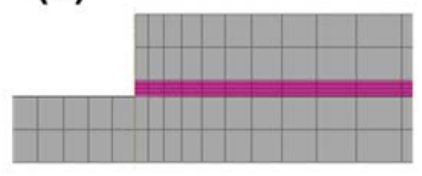

(d)

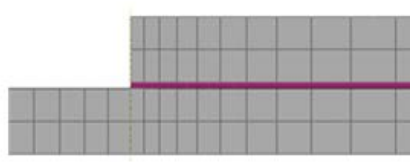

402 Figure 18: Geometry, boundary conditions, and meshing schemes to simulate experimental tests of da Silva et al.[8].

The material properties and damage modeling parameters are shown in Table 2 and were 405 taken from the experimental material characterization results of da Silva et al. [8]. The normal 406 strength of the adhesive was taken from a tension test of Hysol EA9321 and the shear strength of 407 adhesive was calculated from a relationship between adhesive thickness and shear strength 408 considering an adhesive thickness of zero. $\eta$ was not reported; thus, two extreme $\eta$ values were 409 again used in this study. $K$ values were selected to be as high as possible to ensure avoidance of 410 any numerical issues. 
Table 2: Material properties and damage parameters used for FE model of da Silva et al.’s [22] experiment.

\begin{tabular}{ccc}
\hline Steel & Adhesive & \multicolumn{1}{c}{ Damage parameters } \\
\hline$E_{S}=210 \times 10^{3} \mathrm{MPa}$ & $E_{a}=3.87 \times 10^{3} \mathrm{MPa}$ & $\sigma_{\max , n}=45.97 \mathrm{Mpa} ;$ \\
$\nu_{s}=0.30$ & $\sigma_{\max , S}=18.50 \mathrm{Mpa}$ \\
& $\sigma_{\max , t}=18.50 \mathrm{Mpa}$ \\
& $K_{n}=2.40 \mathrm{E} 4 \mathrm{~N} / \mathrm{mm}^{3} ;$ \\
& $K_{S}=K_{t}=7.74 \times 10^{3} \mathrm{~N} / \mathrm{mm}^{3} ;$ \\
& $G_{I}=0.45 \mathrm{~N} / \mathrm{mm} ;$ \\
& $G_{I I}=G_{I I I}=0.90 \mathrm{~N} / \mathrm{mm} ; \eta=[1.55 .0]$
\end{tabular}

All results show that the strength of a single-lap joint reduces when the adhesive thickness 416 increases, which supports the experimental conclusions of da Silva et al. [8]. The experimental 417 and FE results of da Silva et al. [8] and FE simulation results of Sarrado et al. [7] are shown side 418 by side with the current FE model response in

419 Table 3 and Figure 19. The authors' 3D FE element results show close agreement with the 420 experimental results and other previous FE predictions.

Table 3. Modeling results for varying advesive thicknesses compared to literature.

\begin{tabular}{ccccc}
\hline \multirow{2}{*}{$\begin{array}{c}\text { Adhesive } \\
\text { thickness }\end{array}$} & \multirow{2}{*}{$\begin{array}{c}\text { Experimental results } \\
\text { da Silva et al. [22] }\end{array}$} & \multicolumn{3}{c}{ FE modeling results } \\
\cline { 3 - 5 }$(\mathrm{mm})$ & $(\mathrm{kN})$ & $(\mathrm{kN})$ & $(\mathrm{kN})$ & $(\mathrm{kN})$ \\
& & & $(\eta=5.0-1.5)$ & $(\eta=5.0-1.5)$ \\
\hline 0.2 & 11.2 & 11.6 & $10.5-10.8$ & $9.8-10.3$ \\
0.5 & 9.5 & 10.4 & $9.9-10.6$ & $8.9-9.7$ \\
1.0 & 8.2 & 8.8 & $8.5-9.3$ & $7.6-8.4$ \\
\hline
\end{tabular}




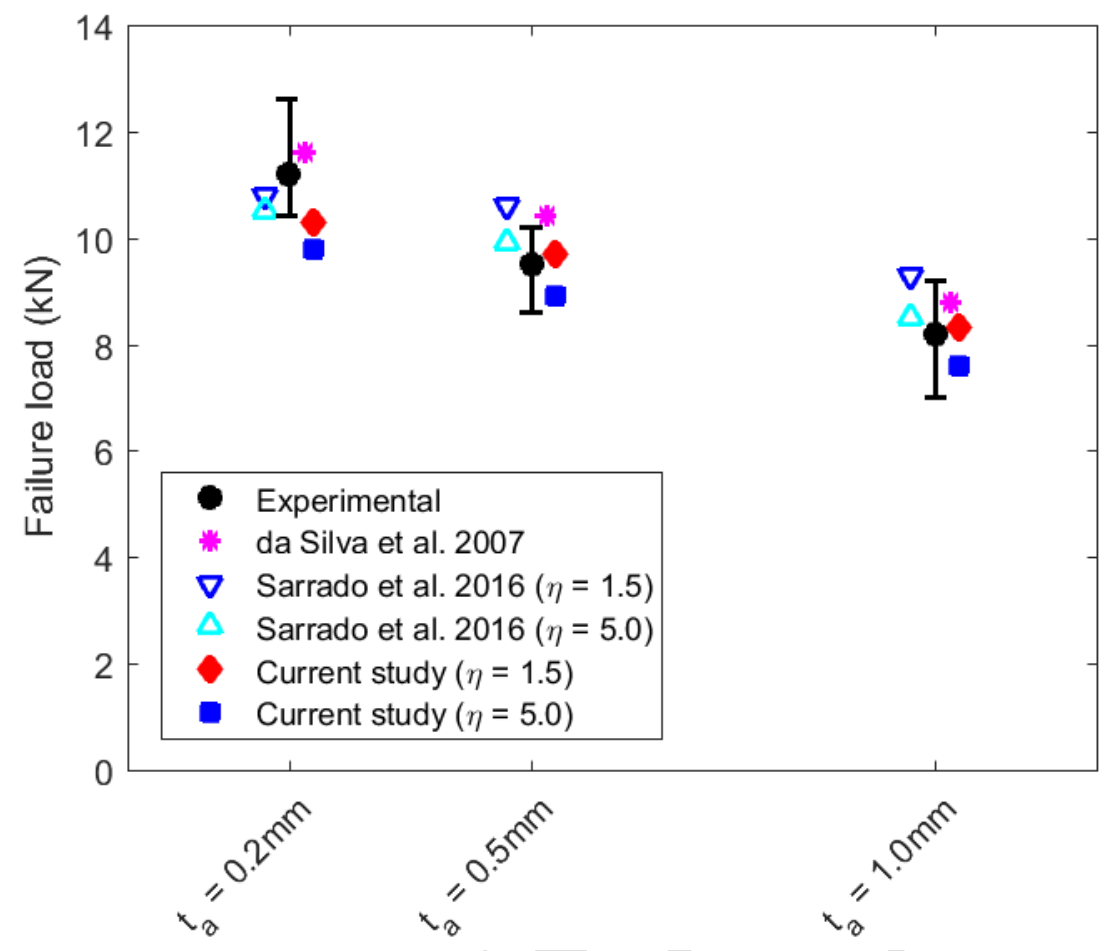

424 Figure 19: Comparison between experimental and FE failure loads for three different bondline 425 thicknesses. Points representing simulation results are offset horizontally for better readability.

426 Figure 20 shows the effects of adhesive thickness and $\eta$ on the load-displacement response 427 of the FE models created in this study. The deformation of the specimens with thicker bondlines 428 is higher due to higher shear deformation of the bondline, which contributes to the deformation in 429 the loading direction. 
(a)

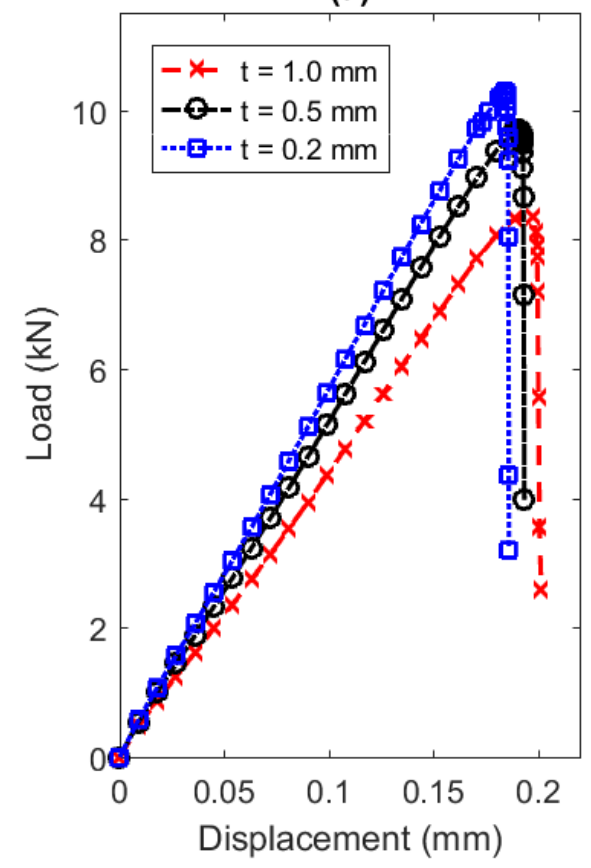

(b)

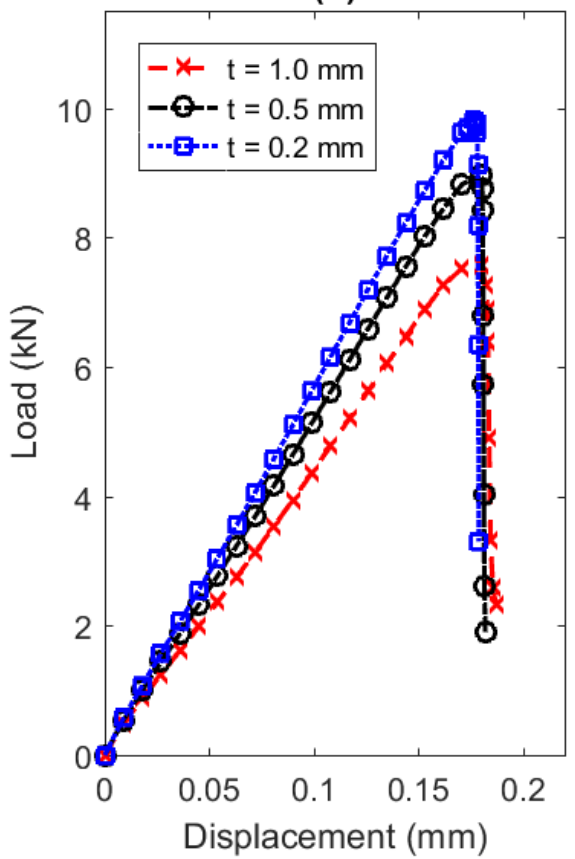

Figure 20: Effect of adhesive thickness variation on predicted load-displacement response of single single-lap joint (a) $\eta=1.5$ and (b) $\eta=5$.

Even though it is evident from the study of da Silva et al. [8] that a thicker adhesive 434 bondline can significantly decrease the bond strength, this may not be true for different joint types and practical adhesive bonded joints where adherents are considerably thicker and stiffer compared to that of the adhesive layer. This can be explained from a mechanical point of view: as the adhesive thickness increases, the eccentricity between the applied loads increases, which creates more bending in the overlapping area. Simulation results also show this causes the peeling stress contribute to the damage onset increases. For this configuration, it was found from the simulation results that the contribution of normal stress in damage onset for $0.2 \mathrm{~mm}$ and $1.0 \mathrm{~mm}$ thick bondline were $41 \%$ and 59\%, respectively. The normal stress attribution increments to the damage 442 onset due to a thicker adhesive layer can vary according to the geometric configuration of the joint 443 and material properties of the adherents. As discussed by Müller and Rath [29], the adhesively 444 bonded joints with thicker adherents have a higher bond strength than that of joints with thinner 445 adherents. Moreover, if the adherents’ thickness is significantly higher than the adhesive thickness 446 in a single-lap joint, a change of adhesive thickness would have a smaller effect on the bond 447 strength. Her and Liu [30] showed that for a double-sided patched joint, thicker adhesives 
experiences less stress. Thus, adhesive thickness needs to be carefully selected considering the geometry of the joint, the type of adhesive, and adherent material properties to obtain an optimum performance.

\section{Conclusions}

In this study, the mechanical influence of an embedded CNT-based sensing layer in the bondline of a single-lap joint was illustrated using experimental and simulation results. From this 454 study the following major development were made.

- From the experimental data, no significant difference in the failure load was observed between the specimen with and without sensing layer. This observation reinforced the potential that sensors embedded within adhesive can be utilized for structural applications without significantly degrading the joint strength.

- A suitable FE modeling methodology was established to model a joint with thick adhesive bondline. The FE model was validated using the experimental results including the failure load, strain distribution in steel substrate, and load-displacement response. It was found that modeling results agree with the experimental data. It is noteworthy to mention that $2 \mathrm{D}$ DIC technique can be used to effectively estimate the end to end deformation of the singlelap specimens.

- A sensing layer was embedded in the bondline in the FE model. It was concluded that for FE modeling, this specific configuration of adhesive bondline, including the sensing layer, does not significantly change the mechanical response and thus is not necessary to model.

- FE element models were developed to investigate the reasons for bond strength degradation observed when thicker adhesive layers were used in a single-lap joint configuration. FE models with various adhesive thicknesses were validated using the experimental results from literature. It was also argued using the current FE simulation results that bond strength does not only depend on the bondline thickness, it also depends on geometry, operational weather, length of overlap and stiffness of substrate etc.

It can be concluded that the sensing enabled adhesive layer can be used for various structural purposes. Moreover, the FE modeling technique used in this research can be utilized to 
model more complex configurations consists with sensing enabled bond line. The FE model would allow us to optimize the system by predict the maximum load carrying capacity.

This study is part of a research project funded under the Federal Highway Administration's Exploratory Advanced Research Program, Award No. DTFH61-13-H-00010. Frank Jalinoos is the project manager and his support and feedback is greatly appreciated. We further thank John Thiravong, research technician at the University of Delaware Center for Composite Materials, for his technical assistance. Finally, we thank Sagar Doshi, PhD Candidate, for his assistance with sample preparation and experimental testing. Any opinions, findings, and conclusions or recommendations expressed in this publication are those of the authors and do not necessarily reflect the view of the Federal Highway Administration.

\section{References}

[1] da Silva LF, Moreira P, Loureiro A. Determination of the strain distribution in adhesive joints using fiber Bragg grating (FBG). J Adhes Sci Technol. 2014;28(14-15):1480-99.

[2] Yashiro S, Wada J, Sakaida Y. A monitoring technique for disbond area in carbon fiber-reinforced polymer bonded joints using embedded fiber Bragg grating sensors: Development and experimental validation. Structural Health Monitoring. 2017;16(2):185-201.

[3] Büyüköztürk O, Haupt R, Tuakta C, Chen J. Remote detection of debonding in FRP-strengthened concrete structures using acoustic-laser technique. In: Nondestructive Testing of Materials and Structures. Springer; 2013. p. 19-24.

[4] Thostenson ET, Chou T. Real-time in situ sensing of damage evolution in advanced fiber composites using carbon nanotube networks. Nanotechnology. 2008;19(21):215713.

[5] Lim AS, Melrose ZR, Thostenson ET, Chou T. Damage sensing of adhesively-bonded hybrid composite/steel joints using carbon nanotubes. Compos Sci Technol. 2011;71(9):1183-9.

[6] Ahmed S, Doshi S, Schumacher T, Thostenson ET, McConnell J. Development of a Novel Integrated Strengthening and Sensing Methodology for Steel Structures Using CNT-Based Composites. J Struct Eng. 2017;143(4).

[7] Sarrado C, Leone FA, Turon A. Finite-thickness cohesive elements for modeling thick adhesives. Eng Fract Mech. 2016;168:105-13.

[8] da Silva LF, Rodrigues T, Figueiredo M, De Moura M, Chousal J. Effect of adhesive type and thickness on the lap shear strength. J Adhes. 2006;82(11):1091-115.

[9] Lewis J. Fast normalized cross-correlation. Vision interface; May 15-19, 1995; Quebec City, Quebec, Canada. ; 1995.

[10] Gonçalves JPM, De Moura MFSF, De Castro PMST. A three-dimensional finite element model for stress analysis of adhesive joints. Int J Adhes Adhes. 2002;22(5):357-65.

[11] Campilho RDSG, Banea MD, Pinto AMG, da Silva LFM, de Jesus AMP. Strength prediction of single- and double-lap joints by standard and extended finite element modelling. Int J Adhes Adhes. 2011 7;31(5):363-72. 
[12] Camanho PP, Davila C, De Moura M. Numerical simulation of mixed-mode progressive delamination in composite materials. J Compos Mater. 2003;37(16):1415-38.

[13] Turon A, Camanho PP, Costa J, Dávila CG. A damage model for the simulation of delamination in advanced composites under variable-mode loading. Mech Mater. 2006;38(11):1072-89.

[14] Turon A, Dávila CG, Camanho PP, Costa J. An engineering solution for mesh size effects in the simulation of delamination using cohesive zone models. Eng Fract Mech. 2007;74(10):1665-82.

[15] de Moura MFSF, Gonçalves JPM, Magalhães AG. A straightforward method to obtain the cohesive laws of bonded joints under mode I loading. Int J Adhes Adhes. 2012 12;39:54-9.

[16] Távara L, Mantič V, Graciani E, Paris F. BEM analysis of crack onset and propagation along fiber-matrix interface under transverse tension using a linear elastic-brittle interface model. Eng Anal Boundary Elements. 2011;35(2):207-22.

[17] Simulia DS. Abaqus 6.11 theory manual. Providence, RI, USA: DS SIMULIA Corp. 2011.

[18] Ye L. Role of matrix resin in delamination onset and growth in composite laminates. Composites Sci Technol. 1988;33(4):257-77.

[19] Camanho PP, Matthews FL. Delamination onset prediction in mechanically fastened joints in composite laminates. J Compos Mater. 1999;33(10):906-27.

[20] Benzeggagh ML, Kenane M. Measurement of mixed-mode delamination fracture toughness of unidirectional glass/epoxy composites with mixed-mode bending apparatus. Compos Sci Technol. 1996;56(4):439-49.

[21] Li G, Lee-Sullivan P, Thring RW. Nonlinear finite element analysis of stress and strain distributions across the adhesive thickness in composite single-lap joints. Compos Struct. 1999;46(4):395-403.

[22] Gonçalves JPM, De Moura MFSF, Magalhães AG, De Castro PMST. Application of interface finite elements to three-dimensional progressive failure analysis of adhesive joints. Fatigue Fract Eng Mater Struct. 2003;26(5):479-86.

[23] Kim K-, Yoo J-, Yi Y-, Kim C-. Failure mode and strength of uni-directional composite single lap bonded joints with different bonding methods. Compos Struct. 2006;72(4):477-85.

[24] Ramberg W, Osgood W. Determination of stress-strain curves by three parameters Technical Note No. 503. National Advisory Committee on Aeronautics (NACA). 1941.

[25] Kim Y, Huh N, Kim Y, Choi Y, Yang J. On relevant Ramberg-Osgood fit to engineering nonlinear fracture mechanics analysis. J Pressure Vessel Technol. 2004;126:277-83.

[26] Tomczyk AJ. MTS Adhesives Project 2: Report no. 5: Summary report: Test methods for adhesive fracture properties. , Oxfordshire: AEA Technology; 1997. Report No.: AEAT-0125.

[27] Dai H, Thostenson ET, Schumacher T. Processing and characterization of a novel distributed strain sensor using carbon nanotube-based nonwoven composites. Sensors. 2015;15(7):17728-47.

[28] Sauer RA. A survey of computational models for adhesion. J Adhes. 2016;92(2):81-120.

[29] Müller B, Rath W. Formulating adhesives and sealants : chemistry, physics and applications. Hannover: Vincentz Network; 2010.

[30] Her S, Liu S. Load transfer in adhesive double-sided patch joints. J Adhes Sci Technol. 2014;28(14-15):151729. 